\title{
Impact of Hybrid and Complex N-Glycans on Cell Surface Targeting of the Endogenous Chloride Cotransporter Slc12a2
}

\author{
Richa Singh, ${ }^{1}$ Mohammed Mashari Almutairi, ${ }^{2}$ Romario Pacheco-Andrade, \\ Mohamed Y. Mahmoud Almiahuob, ${ }^{2}$ and Mauricio Di Fulvio ${ }^{2}$ \\ ${ }^{1}$ Department of Biological Sciences, Boonshoft School of Medicine, Wright State University, 3640 Colonel Glenn Highway, \\ Dayton, OH 45435, USA \\ ${ }^{2}$ Department of Pharmacology \& Toxicology, Boonshoft School of Medicine, Wright State University, 3640 Colonel Glenn Highway, \\ 216 HSB, Dayton, OH 45435, USA
}

Correspondence should be addressed to Mauricio Di Fulvio; mauricio.difulvio@wright.edu

Received 4 May 2015; Revised 29 June 2015; Accepted 7 July 2015

Academic Editor: Afshin Samali

Copyright (c) 2015 Richa Singh et al. This is an open access article distributed under the Creative Commons Attribution License, which permits unrestricted use, distribution, and reproduction in any medium, provided the original work is properly cited.

\begin{abstract}
The $\mathrm{Na}^{+} \mathrm{K}^{+} 2 \mathrm{Cl}^{-}$cotransporter-1 (Slc12a2, NKCC1) is widely distributed and involved in cell volume/ion regulation. Functional NKCC1 locates in the plasma membrane of all cells studied, particularly in the basolateral membrane of most polarized cells. Although the mechanisms involved in plasma membrane sorting of $\mathrm{NKCCl}$ are poorly understood, it is assumed that $\mathrm{N}$ glycosylation is necessary. Here, we characterize expression, N-glycosylation, and distribution of NKCC1 in COS7 cells. We show that $\sim 25 \%$ of $\mathrm{NKCC1}$ is complex N-glycosylated whereas the rest of it corresponds to core/high-mannose and hybrid-type Nglycosylated forms. Further, $\sim 10 \%$ of NKCC1 reaches the plasma membrane, mostly as core/high-mannose type, whereas $\sim 90 \%$ of NKCC1 is distributed in defined intracellular compartments. In addition, inhibition of the first step of N-glycan biosynthesis with tunicamycin decreases total and plasma membrane located NKCC1 resulting in almost undetectable cotransport function. Moreover, inhibition of N-glycan maturation with swainsonine or kifunensine increased core/hybrid-type NKCC1 expression but eliminated plasma membrane complex $\mathrm{N}$-glycosylated $\mathrm{NKCC1}$ and transport function. Together, these results suggest that (i) $\mathrm{NKCCl}$ is delivered to the plasma membrane of COS7 cells independently of its $\mathrm{N}$-glycan nature, (ii) most of $\mathrm{NKCC1}$ in the plasma membrane is core/hybrid-type N-glycosylated, and (iii) the minimal proportion of complex N-glycosylated NKCC1 is functionally active.
\end{abstract}

\section{Introduction}

The $\mathrm{Na}^{+} \mathrm{K}^{+} 2 \mathrm{Cl}^{-}$cotransporters (NKCCs) belong to the family of solute carriers Slc12a which comprise several homologous genes: Slc12a1 (NKCC2), Slc12a2 (NKCC1), Slc12a3 $\left(\mathrm{Na}^{+}-\right.$ $\mathrm{Cl}^{-}$cotransporter, NCC), Slcl2a4-7 $\left(\mathrm{K}^{+}-\mathrm{Cl}^{-}\right.$cotransporters, KCC1-4), and Slc12a9 (CIP1) [1]. NKCCs are bumetanide(BTD-) sensitive ion transporters that accumulate $\mathrm{Cl}^{-}$in cells using the energy stored in the $\mathrm{Na}^{+}, \mathrm{K}^{+}$, and $\mathrm{Cl}^{-}$chemical gradients. NKCCs play important roles in regulating the intracellular chloride concentration $\left(\left[\mathrm{Cl}^{-}\right]_{\mathrm{i}}\right)$, a key determinant of GABAergic signaling [2], salt/fluid [3], and hormone secretion [4].

The human SLC12A2 gene encodes at least three splice variants represented in the Reference Sequence Database of the National Center for Biotechnology Information (RefSeq) by accessions numbers NM_001046 (SLC12A2 v1, NKCC1a), NM_001256461 (SLC12a2 v2, NKCC1b), and NR_046207 (SLC12A3 v3). Except for the latter, recently annotated as a long noncoding RNA (lncRNA), NKCCla and NKCC1 $b$ transcripts encode proteins of $\sim 130 \mathrm{kDa}$ with predicted 12 transmembrane domains and two large intracellular $\mathrm{N}$ - and C-termini [5]. NKCC1 $b$ lacks 16 C-terminal residues as a consequence of alternative splicing of exon 21 [6]. Both NKCC1a and $\mathrm{NKCC} 1 b$ exhibit similar functional properties but differ in their expression pattern [7]. With some exceptions, such as tubular cells of the thick ascending limb of Henle's loop (TALH) [8] or glucagon-secreting cells of the endocrine pancreas $[9,10]$, NKCC1 has been found in all mammalian cells examined so far at the protein or functional level [11]. 
In particular, NKCC1 localizes in the basolateral side of most epithelial cells [12-15] and polarized cell lines [16-18]. In nonpolarized cells including primary astrocytes [19] or insulin-secreting cells $[10,20]$, NKCC1 is found abundantly in cytoplasmic compartments. This is not extraordinary, as any transmembrane proteins including NKCCs are expected, to some extent, to be found in intracellular membrane compartments such as the endoplasmic reticulum (ER) where the transporter is synthesized and in the Golgi apparatus where complex $\mathrm{N}$-glycosylation takes place $[16,21]$. It is this latter step the one considered necessary for NKCC1 delivery to the plasma membrane [16]. Although N-glycosylation appears to play a role in membrane trafficking of the closely related NKCC2 [22-26], the N-glycan nature of NKCC1 and the impact of complex $\mathrm{N}$-glycosylation on plasma membrane insertion of this transporter are unknown.

The objective of the present work was to determine the following: (i) the variants of NKCC1 expressed in COS7 cells, a model wherein the secretory pathway has been extensively characterized, (ii) the overall N-glycan nature of endogenous $\mathrm{NKCC1}$, (iii) its cellular location, and (iv) the role of complex $\mathrm{N}$-glycosylation on plasma membrane targeting and basal transport function of NKCC1. The results shown here were partially presented as posters in the annual meetings of the American Society for Biochemistry and Molecular Biology (ASBMB 2011-13) and constitute the core of RS Master's Thesis in Pharmacology and Toxicology.

\section{Materials and Methods}

2.1. Materials. Pfx DNA-polymerase, RNase-OUT, SuperScript-III reverse transcriptase, random hexamers, transfection reagents, and culture supplements including antibiotics were from Invitrogen/Life Technologies (Carlsbad, CA); dNTPs and ExoSAP-it were from Affimetrix/USB (Cleveland, $\mathrm{OH}$ ); custom DNA primers were from Integrated DNA Technologies (Coralville, IA); the RNAeasy kit for RNA purification was from Qiagen (Valencia, CA). Human brain complementary DNA (cDNA) was obtained from Zyagen (San Diego, CA). Precasted SDS-polyacrylamide gels, running buffer, protein molecular weight (MW) markers, protease/phosphatase inhibitor cocktails, and SuperSignal West Pico Chemiluminescence kits were form Pierce (Thermo Scientific, Rockford, IL). General chemicals, cycloheximide, bumetanide, and brefeldin A were from Sigma (Saint Louis, MO). All microscopy materials were from Electron Microscopy Sciences (Hatfield, PA) and Vector Labs (Burlingame, CA). Tissue culture media and serum were from Thermo Fisher Sci. (Pittsburg, PA). Tunicamycin (TUN), kifunensine (KIF), and swainsonine (SWN) were from Cayman Chemicals (Ann Arbor, MI). DNA ladders, peptide-N-glycosidase F (PNGaseF), and endoglycosidase $\mathrm{H}$ (EndoH) were from New England Biolabs Inc. (Ipswich, MA).

2.2. Antibodies. Monoclonal antibodies against NKCC1 (T4), the lysosomal-associated membrane protein-1 (LAMP), $\beta$ actin, and tubulin were from Developmental Studies
Hybridoma Bank (DSHB, University of Iowa). Purified mouse anti-Rab11 was from BD Transduction Laboratories (San Jose, CA). Anti-human calreticulin (CRT) and NKCC1 (ckNKCC1) antibodies raised in chicken were from Thermo Scientific (Rockford, IL). Rabbit anti-human $\alpha$-mannosidase II (Man2) antibodies were from LifeSpan BioSciences Inc. (Seattle, WA). Conjugated secondary antibodies for immunofluorescence application or Western blotting were from Jackson Immunoresearch Laboratories Inc. (West Grove, PA).

2.3. Cell Culture and Stable Transfection. Chlorocebus aethiops (green monkey) kidney fibroblast COS7 cells (ATCC, Manassas, VA) were grown and maintained in 6-well plates (BioLite, Thermo Scientific) in high-glucose (25 mM) Dulbecco's modified Eagle medium (DMEM) supplemented with $10 \%$ fetal bovine serum (FBS), $4 \mathrm{mM}$ L-glutamine, $1 \mathrm{mM}$ sodium pyruvate, $100 \mathrm{IU} / \mathrm{mL}$ penicillin, $100 \mu \mathrm{g} / \mathrm{mL}$ streptomycin, and $0.25 \mu \mathrm{g} / \mathrm{mL}$ amphotericin B. Cells were grown in $5 \% \mathrm{CO}_{2}$ at $37^{\circ} \mathrm{C}$ and media were changed every $2-3$ days until $\sim 90 \%$ confluence. To silence endogenous NKCC1 expression, early passaged COS7 cells were transfected with human lentiviral constructs encoding green fluorescent protein (GFP) and short-hairpin RNAs (shRNAs) against the fourth exon of human NKCC1 transcripts (V2LHS_93958, OpenBiosystems, Huntsville, AL). As control, we used constructs lacking shRNA sequences. Transfection was performed by using Lipofectamine 2000 and following the manufacturer's instructions. Two days after transfection, cells were washed and observed under inverted fluorescence microscope to identify GFP-expressing cells and to estimate transfection efficiency. Then, fully supplemented media containing puromycin $(2.5 \mu \mathrm{g} / \mathrm{mL})$ were added to initiate the selection process. Western blotting with T4 antibodies was performed to screen stably silenced GFP-expressing COS7 cells.

2.4. RNA Extraction and RT-PCR. First-strand cDNA synthesis was initiated with $\sim 1 \mu \mathrm{g}$ of total RNA, $250 \mathrm{ng}$ of random hexamers, $500 \mu \mathrm{M}$ of dNTPs, $10 \mathrm{mM}$ of DTT, 40 units of RNase-OUT, and 200 units of SuperScript-III reverse transcriptase (RT) in a final volume of $20 \mu \mathrm{L}$ at $50^{\circ} \mathrm{C}$ for $50 \mathrm{~min}$. The thermostable polymerase reaction (PCR) was subsequently performed as described in detail elsewhere [10]. Simultaneous screening of NKCCl $a$ and NKCC1 $b$ transcripts in COS7 cells was performed following the strategy developed by Mao et al. [27] and adapted to our cell model. PCR oligonucleotide primer sets were designed using human NKCC1 transcript sequences of reference (RefSeq accession numbers NM_001046 and NM_001256461) as templates. The following sets of primers were used (from $5^{\prime}$ to $3^{\prime}$ ): NKCC1516a/468b sense: ATG GAG TAG TGG TTA TTC GCC TAA AAG AAG, NKCC1-516a/468b antisense: TGA TAT CAG AAA AGT CTA TCC GGA ACT TGC; NKCC1608a/560b sense: ACA TAC AAT ATG GAG TAG TGG TTA TTC GCC, NKCC1-608a/560b antisense: ATG AAG TCT GTA TGG CTC AAT GAT TTC CTC (see Figure 1(a), for a graphic representation of them). Control RT-PCR 


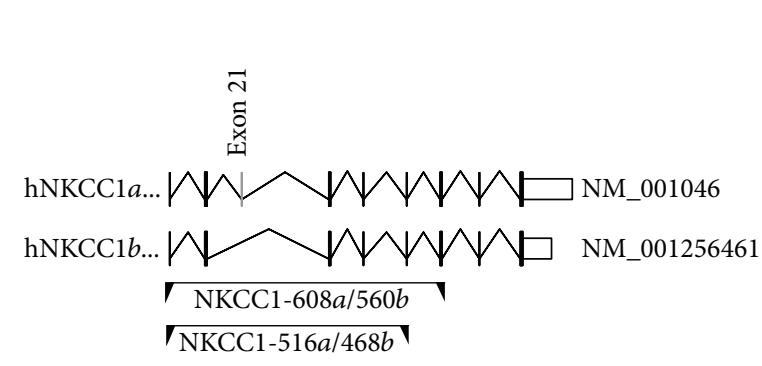

(a)

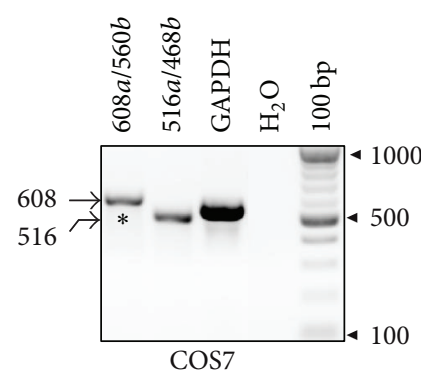

(b)

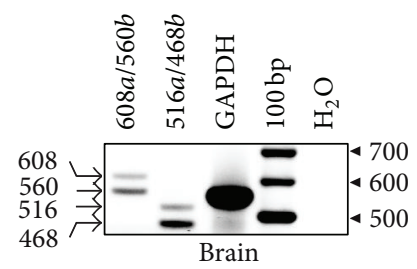

(c)

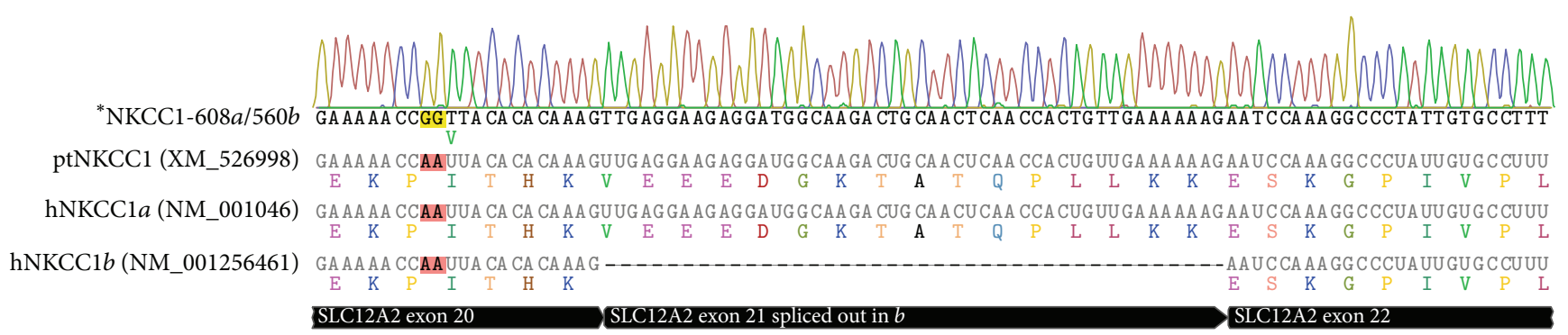

(d)

FIGURE 1: NKCC1 $a$ transcripts are expressed in COS7 cells. (a) Representation of the last nine exons (boxes) of the human SLC12A2 gene. Alternative spliced exon 21 is indicated as a grey box in NKCCla (NM_001046). Introns are represented with V-shaped lines. White boxes represent $3^{\prime}$-UTRs. Underneath, shown are the primer sets used to coamplify NKCCla and NKCC1b mRNAs (represented as opposite arrowheads connected by a line). These primers are labeled according to the size in bp of the expected amplicons (see text). (b) Shown is a representative $2 \%$ agarose gel where bands of predicted sizes for NKCCla are detected ( $608 \mathrm{bp}$ and $516 \mathrm{bp}$ ). (c) In human brain, bands of predicted sizes for NKCCla and NKCC1b are coamplified: $608 \mathrm{bp}+560 \mathrm{bp}$ and $516 \mathrm{bp}+468 \mathrm{bp}$, respectively. As positive control, RTPCR reactions amplified GAPDH $(555 \mathrm{bp})$. As negative control, RT-PCR reactions were performed using $\mathrm{H}_{2} \mathrm{O}$ instead of total RNA and GAPDH-555 primer sets. (d) Representative DNA sequence chromatogram corresponding to amplicons obtained with primer set NKCC1$608 a / 560 b$ encompassing exons 20, 21, and 22 in NKCC1 mRNAs. The sequences obtained from COS7 cells were aligned against chimpanzee (XM_526998) and human NKCCl transcripts of reference. The sequence difference found in that region is highlighted.

reactions were performed by using validated primers for human glyceraldehyde phosphate dehydrogenase (GAPDH, RefSeq accession number NM_002046): GAPDH-555 sense: GTG AAG GTC GGA GTC AAC GGA TTT, GAPDH555 antisense: CAC AGT CTT CTG GGT GGC AGT GAT [28]. NKCC1 primer design and in silico analysis of sequences obtained were performed using the software package Geneious R7 (Biomatters, Auckland, New Zealand). The nucleotide sequence identity of DNA fragments present in PCR reaction tubes was determined after in situ treatment with ExoSAP-it (Affimetrix/USB, Cleveland, $\mathrm{OH}$ ) to eliminate excess nucleotides and single stranded DNA. These noncloned but purified amplicons were sequenced by PCR using the same primer sets used to generate them (Beckman Coulter Genomics, Beverly, MA).

2.5. Western Blotting. COS7 cells were placed on ice and washed twice with cold phosphate buffered saline (PBS) and protein extracts were obtained by collecting cells with the help of a rubber policeman in the presence of lysis buffer [50 mM Tris- $\mathrm{HCl}$ pH 7.5, $1 \mathrm{mM}$ EDTA pH 8.0, $1 \mathrm{mM}$ EGTA pH 8.0, 0.1\%(v/v) $\beta$-mercaptoethanol, and $1 \%$ Triton X100] supplemented with phenylmethylsulfonyl fluoride (PMSF, $25 \mathrm{mM}$ ) and protease/phosphatase inhibitors cocktails. Tissues lacking NKCC1 (obtained from NKCC $1{ }^{\mathrm{KO}}$ mice, generated by Dr. Gary Shull, University of Cincinnati [29] and bred in our animal facility), were finely chopped on ice-cold PBS, immediately washed, and resuspended in complete lysis buffer. Samples were vigorously passed through a syringe needle while incubated for $1 \mathrm{~h}$ on ice. The total protein content of cell or tissue lysates was determined using Bradford's method (BioRad, Hercules, CA). Fifty $\mu \mathrm{g}$ of total protein in a final volume of $20 \mu \mathrm{L}$ was mixed with an equal volume of loading buffer ( $8 \%$ SDS, $125 \mathrm{mM}$ Tris-HCl, pH-6.8, 20\% glycerol, $0.02 \%$ bromophenol blue, and $100 \mathrm{mM}$ dithiothreitol) and boiled 5 minutes before loading samples onto precasted TrisHEPES 4-20\% SDS-PAGE protein gels. Samples were separated by electrophoresis for $\sim 1 \mathrm{~h}$ at $100 \mathrm{mV}$. Electrophoresed proteins were then electrotransferred onto PVDF membranes (Millipore, MA) at $4^{\circ} \mathrm{C}$ for $\sim 2 \mathrm{~h}$. Membranes were air-dried and blocked with $5 \%$ bovine serum albumin (BSA) in $50 \mathrm{mM}$ Tris, $150 \mathrm{mM} \mathrm{NaCl}$ supplemented with $0.05 \%$ Tween 20 (TBS-T) at room temperature. After blocking, membranes were cut and blotted overnight at $4^{\circ} \mathrm{C}$ using ckNKCC1 antibodies in $5 \%$ BSA/TBS-T. $\beta$-actin, tubulin, or GAPDH expression was used as internal loading controls. After blotting, membranes were washed twice with TBS-T for $5 \mathrm{~min}$ using gentle rocking. To develop antigen-antibody reactions, membranes were incubated with horseradish peroxidase(HRP-) conjugated secondary antibodies directed against 
primary immunoglobulins for $1 \mathrm{~h}$ at room temperature. Membranes were then washed 5 min three times in TBS$\mathrm{T}$ and developed by using chemiluminescence. Blots were visualized and images captured by using the Chemi-Doc MP Imaging system (BioRad, Hercules, CA). When required, the relative amount of $\mathrm{NKCCl}$ present in immunoblots was determined by normalizing the densitometry signal to $\beta$-actin, tubulin, or GAPDH. Densitometry analysis was performed on digitalized blot images by using Image Lab Quantitative software (BioRad, Hercules, California) or ImageJ (NIH).

2.6. Deglycosylation. To determine the N-glycan nature of $\mathrm{NKCC1}, 50 \mu \mathrm{g}$ of cell lysates were subjected to enzymatic digestion with $50 \mathrm{kU}$ of PNGaseF, an enzyme that cleaves all $\mathrm{N}$-linked glycans irrespective of their nature, or EndoH, an enzyme that cleaves hybrid-type or high-mannose but not complex-type N-glycans. Digestions were performed following provider's instructions. Digested NKCC1 was immunodetected by following the immunoblotting procedures explained above.

2.7. Plasma Membrane Biotinylation. The extracellular surface of COS7 cells was biotinylated following published protocols [30] with the modifications published by Ortiz [31] and Nezu et al. [21]. Briefly, confluent COS7 cells growing under control conditions or in the presence of $\mathrm{N}$ glycosylation inhibitors in DMEM without FBS for $16 \mathrm{~h}$ at $37^{\circ} \mathrm{C}$ were washed twice with ice-cold PBS and collected. Cells were then pelleted at $2500 \times \mathrm{g} 5 \mathrm{~min}$, resuspended in $1 \mathrm{mM}$ Sulfo-NHS- (N-hydroxysuccinimide-) biotin, and incubated for $1 \mathrm{~h}$ at $4^{\circ} \mathrm{C}$ with gentle rocking. Biotinylated cells were collected by centrifugation at $2500 \times \mathrm{g}$ for $4 \mathrm{~min}$, washed three times with ice-cold PBS, and lysed. To separate biotinylated plasma membranes from the whole lysate mixture, $50 \mu \mathrm{g}$ of protein lysates were incubated in $150 \mu \mathrm{L}$ streptavidinconjugated agarose resins (50\% slurry plus $0.02 \% \mathrm{NaN}_{3}$ ) overnight at $4^{\circ} \mathrm{C}$ with gentle rocking. Beads were then centrifuged at $15,000 \times \mathrm{g}$ for $5 \mathrm{~min}$ at $4^{\circ} \mathrm{C}$ and washed three times with lysis buffer, three times with $1 \mathrm{M} \mathrm{NaCl}$, and twice with PBS. Beads were then resuspended in $25 \mu \mathrm{L}$ of SDS loading buffer, denatured for $5 \mathrm{~min}$ at $100^{\circ} \mathrm{C}$, subjected to SDS-PAGE and immunoblotted. As control of the purified membrane fraction, we used GAPDH, a cytoplasmic enzyme not present in biotinylated plasma membrane fractions [32].

\subsection{Immunofluorescence and Coimmunolocalization Analy-} sis. COS7 cells were grown on glass coverslips following described procedures [33]. Briefly, cells were cultured in complete DMEM until $\sim 60-70 \%$ confluence was reached and then overnight in the absence of FBS plus or minus drugs before experiments. Cells were washed twice in PBS and immediately fixed by covering the slides in absolute methanol and incubating them for $10 \mathrm{~min}$ at $-20^{\circ} \mathrm{C}$. Cells were permeabilized in $4 \% p$-formaldehyde containing $0.25 \%$ Triton X-100 for $15 \mathrm{~min}$ at $4^{\circ} \mathrm{C}$. After washing twice with icecold PBS, cells were blocked against nonspecific staining by incubating them in $3 \%$ goat serum for $1 \mathrm{~h}$ at $4^{\circ} \mathrm{C}$. Cells were then carefully washed three times with PBS at room temperature and incubated with T4 (1:500) alone or in combination with organelle markers: CRT $(1: 500)$, LAMP (1:1000), Rab11 (1:500), or Man2 (1:500), at $4^{\circ} \mathrm{C}$ overnight. The next day, immunolabeled cells were carefully washed off primary antibodies four times with ice-cold PBS and immediately incubated with fluorescently labeled secondary antibodies (Cy3- or FITC-conjugated) diluted in PBS (1:1000-2000) for $2 \mathrm{~h}$ at $4^{\circ} \mathrm{C}$. After washing cells four times with PBS, the coverslips were taken from the wells and air-dried. Then, $14 \mu \mathrm{L}$ of Vectashield mounting medium containing $4^{\prime}-6$ diamidino-2-phenylindole (DAPI) was added to the center of the dried coverslips and immediately placed upside down on microscope slides $(24 \times 50 \mathrm{~mm})$. Mounted slides were visualized in an Olympus Epi-Fluorescence microscope attached to a color camera using 60x oil objective and FITC/Cy3/DAPI fluorescence filters. Photomicrographs were obtained using Diagnostics Instrument Spot 6 digital camera and MetaVue software (Molecular Devices, Sunnyvale, CA). Coimmunolabeling analysis was based on relative semiquantitation of overlapping pixels observed in high-resolution digital images taken using different filters/channels and superimposed (overlays). This estimation was performed in silico and expressed as \% overlap. We considered colocalization when pixels of different channels shared the same bit area. All pixels were analyzed based on their intensity as interpreted in the algorithms used by the software suite Metamorph (Molecular Devices, Sunnyvale, CA) with minimal user interference. In general, selected areas of the cells were measured for specific florescence signal and the data obtained was plotted using Graphpad Prism v5 (San Diego, CA). To estimate colocalization, heat-maps were produced by counting pixels for each gray value on 8-bit transformed overlay pictures using the heat-map plugin of ImageJ (NIH).

2.9. Chloride Uptake. COS7 cells were seeded onto 6-well plastic plates and grown until $\sim 80 \%$ confluence. Cells were washed and preincubated in $\mathrm{Cl}^{-}$-free isotonic solution containing (in mM) 20 Tris-HEPES ( $\mathrm{pH} 7.4$ ), $130 \mathrm{Na}^{+}$gluconate, $5 \mathrm{~K}^{+}$gluconate, $2 \mathrm{Ca}^{2+}$ gluconate, $1 \mathrm{MgSO}_{4}$, and 10 glucose, for $60 \mathrm{~min}$ at room temperature. After this preincubation period, media were aspirated and replaced by an isotonic solution where gluconate salts were replaced in a mol-to-mol basis with the respective $\mathrm{Cl}^{-}$salts. $\mathrm{Cl}^{-}$uptake was terminated with three washes in ice-cold $\mathrm{Cl}^{-}$-free isotonic solution and the ionic content of cells released by incubating them in $0.25 \mathrm{~N} \mathrm{NaOH}$ at RT for $30 \mathrm{~min}$. After neutralization with glacial acetic acid, aliquots were accurately taken for protein determination and measurement of $\mathrm{Cl}^{-}$with calibrated ionselective electrodes (Thermo Sci-Orion). The relationship between concentration of $\mathrm{Cl}^{-}$and the response of the $\mathrm{Cl}^{-}$ electrode in $\mathrm{mV}$ at $25^{\circ} \mathrm{C}$ is described by the Nernst equation: $E(\mathrm{mV})=k-59.16 \times \log \left[\mathrm{Cl}^{-}\right]$. Electrode responses were converted to $\left[\mathrm{Cl}^{-}\right]$in standard curves $E$ versus $\log \left[\mathrm{Cl}^{-}\right]$. Then, net $\mathrm{Cl}^{-}$uptake was calculated and expressed as nmol of $\mathrm{Cl}^{-}$per $\mu \mathrm{g}$ of total protein. Bumetanide- (BTD-) sensitive $\mathrm{Cl}^{-}$uptake (NKCC-mediated) was defined as the difference between $\mathrm{Cl}^{-}$accumulated in 5 minutes and that obtained in the presence of $10 \mu \mathrm{M}$ BTD. 
Note. The response of the electrode to variable concentrations of BTD was negligible.

2.10. Statistical Analysis. Analysis of multiple group differences was performed using one-way analysis of variance (ANOVA) followed by Student-Newman-Keuls' test. A $p$ value less than 0.05 was used as the criteria of statistical significance.

\section{Results}

3.1. COS7 Cells Express NKCCla. To identify NKCC1 splice variants expressed in COS7 cells, we used RT-PCR and two sets of primers encompassing the junction between exons 20 , 21 [48 base pairs (bp)], and 22. These sets of primers named NKCC1-608a/560b and NKCC1-516a/468b are predicted to coamplify NKCCl $a$ and NKCCl $b$ mRNAs as bands of 608 or $516 \mathrm{bp}$ and 560 or $468 \mathrm{bp}$, respectively. A representation of these primers relative to the relevant region of human NKCC1 transcripts is shown in Figure 1(a). As shown in Figures 1(b) and 1(c), NKCCla transcripts bands of 608 and $516 \mathrm{bp}$ are detected in COS7 cells whereas bands of 560 and $468 \mathrm{bp}$ corresponding to $\mathrm{NKCCl} b$ were not coamplified suggesting that NKCCla mRNAs are expressed in these cells. The undetectable levels of NKCC1 $b$ transcripts are not related to poor primer design; NKCCla and NKCCl $b$ mRNAs are codetected as bands of $608,560,516$, and $468 \mathrm{bp}$ in cDNA samples obtained from human brain, an abundant source of $\mathrm{NKCCl} a$ and NKCCl$b$ transcripts [7]. To further corroborate the presence of NKCCla in COS7 cells, the whole RTPCR reaction carried out with primer set NKCC1-608a/560b (asterisk in Figure 1(b)) was purified and sequenced. As shown in Figure 1(d), the nucleotide sequence obtained identified exon 21 of NKCCla but not the junction of exons 20 and 22 demonstrating that NKCC1-608a/560b amplified NKCCla mRNAs from COS7 cells. Of note, we did not find evidence of Slc12a2 $v 3$ lncRNAs in human brain or COS7 cells (results not shown).

To confirm NKCC1 expression at the protein level in COS7 cells, we performed immunoblotting experiments using two different antibodies directed against human NKCC1. These are T4, a thoroughly characterized, widely used, and validated mouse monoclonal antibody [34] and a recently available polyclonal antibody raised in chicken (ckNKCC1). As shown in Figure 2(a), T4 and ckNKCC1 detect NKCC1 in COS7 cells as two major bands, one of $130 \mathrm{kDa}$ and another of $\sim 170 \mathrm{kDa}$, considered the core/highmannose and complex N-glycosylated forms of the transporter, respectively $[16,35-39]$. To minimize the possibility of cross-reaction with unrelated proteins, we tested ckNKCC1 in blots of protein extracts obtained from $\mathrm{NKCC}^{\mathrm{KO}}$ tissues. Figures 2(b) and 2(c) show that T4 and ckNKCC1 do not detect proteins in liver or kidney of $\mathrm{NKCC}^{\mathrm{KO}}$ mice, respectively. It is important to note that the kidney is the most abundant source of NKCC2 [3], the only known crosstarget of T4 [40]. To validate T4 in our cell model, this antibody was tested in COS7 cells depleted of endogenous $\mathrm{NKCC1}\left(\mathrm{COS}^{\mathrm{shNKCC1}}\right)$. As control, COS7 cells were stably transfected with constructs lacking shRNAs $\left(\mathrm{COS}^{\text {shControl }}\right)$. Figure 2(d) shows that $\mathrm{T} 4$ does not detect $\mathrm{NKCC1}$ in protein extracts from $\mathrm{COS}_{7} 7^{\text {shNKCC1}}$, a finding that correlates at the cellular level. Indeed, T4 was unable to detect immunoreactive NKCC1 in fixed COS7 $7^{\text {shNKCC1 }}$ cells (Figures $2(\mathrm{e})-2(\mathrm{~h})$ ) suggesting that the antibody is specific of NKCC1 in COS7 cells under our experimental conditions. To further support the concept that $\mathrm{T} 4$ and ckNKCCl produce comparable results, normal COS7 cells were immunolabeled in parallel with each antibody. As shown in Figures 2(i) and 2(j), T4 and ckNKCCl detect NKCCl distributed throughout the cells in a reticular, granular, or vesicular pattern and fairly concentrated toward one of the poles of the nucleus as well as in the perinuclear region and near or at the plasma membrane. Taken together, these results suggest that core/highmannose/hybrid/complex N-glycosylated NKCCla is the sole $\mathrm{NKCC1}$ variant expressed in COS7 cells and that ckNKCC1 and $\mathrm{T} 4$ antibodies may be used to determine NKCC1 protein expression patterns at the molecular and cellular levels in our cell model.

3.2. A Small Proportion of Endogenous NKCC1 Is Complex N-Glycosylated. Enzymatic deglycosylation coupled to immunoblotting was used to determine the basal $\mathrm{N}$ glycosylation state and global N-glycan nature of endogenous NKCC1 expressed in COS7 cells. To this end, protein lysates were treated with PNGaseF or EndoH, enzymes that cleave all $\mathrm{N}$-linked glycans or high-mannose/hybrid-type, respectively. As shown in Figure 3(a), treatment with PNGaseF resulted in a significant, nearly complete elimination of the $\sim 170 \mathrm{kDa}$ band and a parallel $\sim 2$-fold increase in core NKCC1 levels $(\sim 130 \mathrm{kDa})$. These results suggest that at least half of total $\mathrm{NKCC1}$ expressed in COS7 cells is core/high-mannose Nglycosylated. Further, as shown in Figure 3(b), treatment of COS7 cells protein extracts with EndoH resulted in 50\% decrease of the $\sim 170 \mathrm{kDa}$ bands of NKCC1 indicating that half of the total $\mathrm{N}$-glycan composition of $\mathrm{NKCCl}$ is of the core/high-mannose/hybrid-type. To visualize these changes, immunoblots were subjected to densitometry analysis. Figures 3(c) and 3(d) show the estimated relative contribution of core and hybrid- and complex-type N-glycans to the total pool of endogenous NKCCl, a parameter calculated as percentage densitometry increase in the bands of $\sim 130 \mathrm{kDa}$ after deglycosylation. To interpret these results, we applied the following reasoning: if the \% densitometry signal of $\sim 130 \mathrm{kDa}$ bands increased twice after PNGaseF treatment, then $50 \%$ of total NKCC1 is N-glycosylated. Similarly, if the $\%$ densitometry signal of $\sim 170 \mathrm{kDa}$ bands after EndoH treatment was half, then $25 \%$ of total NKCC1 is hybridtype N-glycosylated. Therefore, our results suggest that $25 \%$ of total NKCC1 expressed in COS7 cells is complex Nglycosylated.

3.3. Core/High-Mannose, Hybrid, and Complex N-Glycosylated NKCC1 Reach the Plasma Membrane. It is generally accepted that complex N-glycosylation of NKCCs is necessary for plasma membrane insertion [16, 21, 23-26]. Therefore, the results presented in Figure 3 predict that at least 


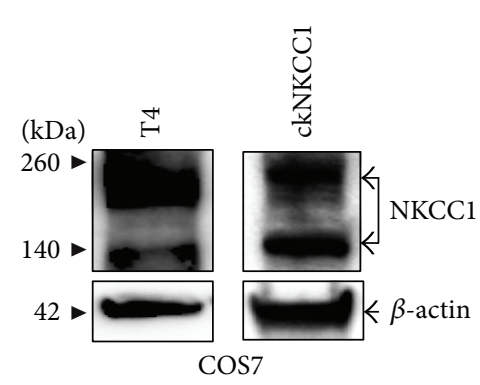

(a)
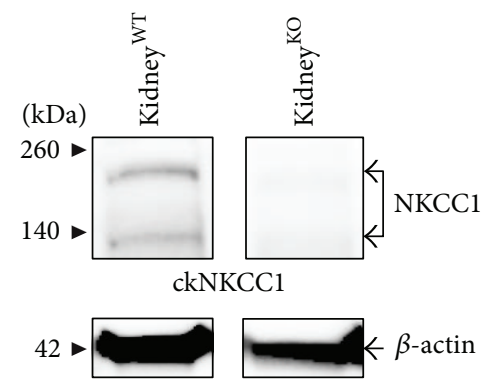

(c)

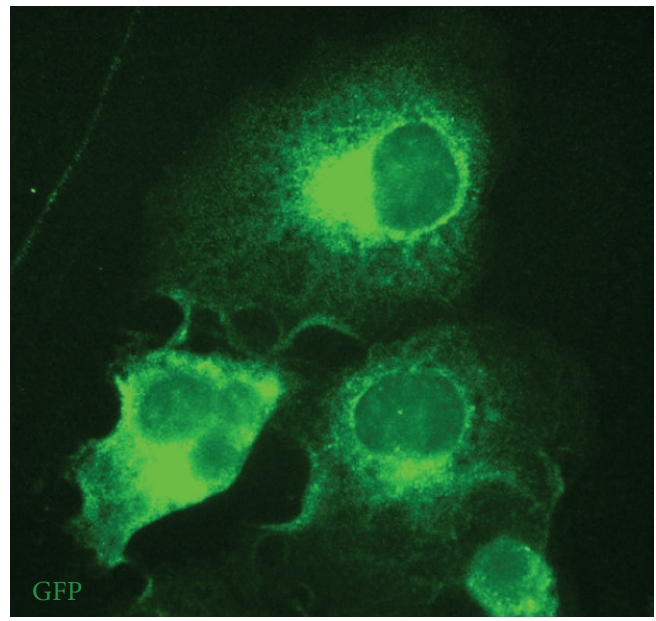

(e)

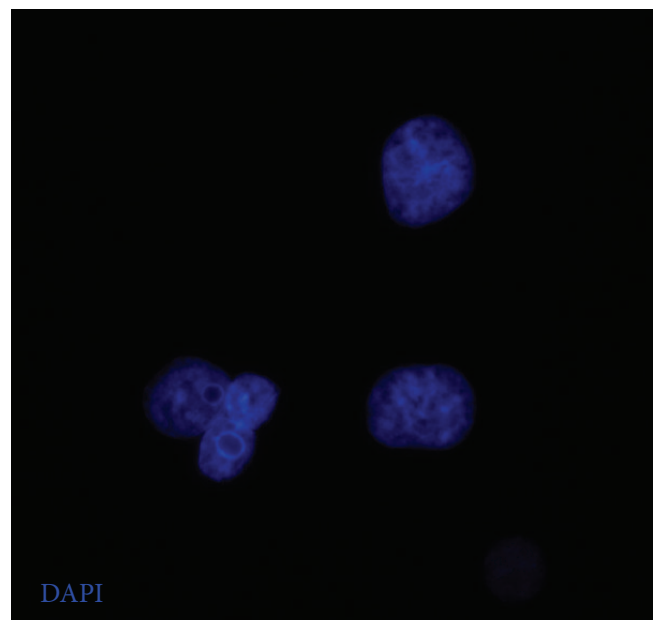

(g)

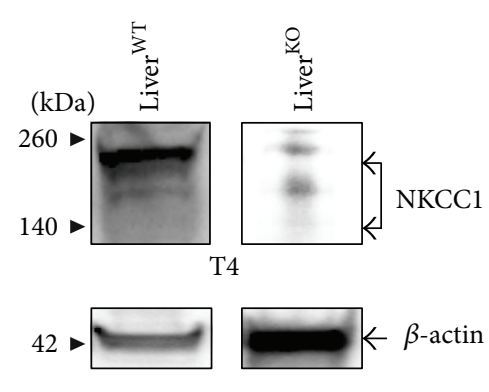

(b)

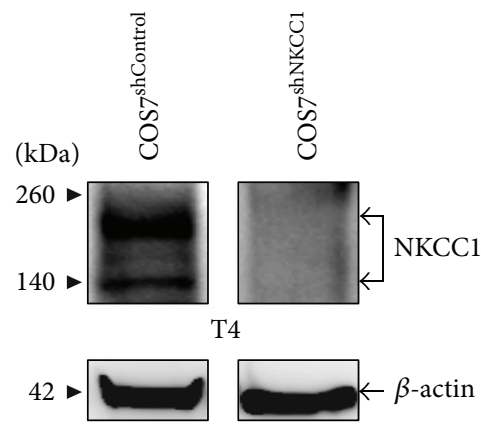

(d)

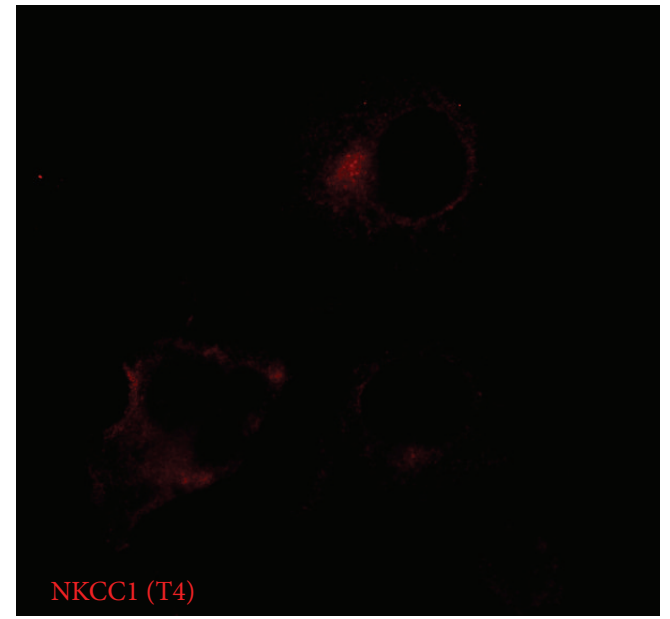

(f)

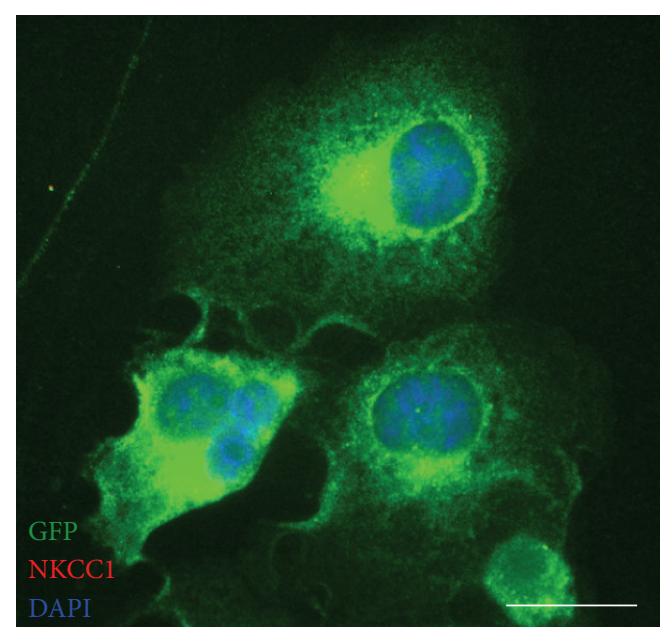

(h)

FIGURE 2: Continued. 


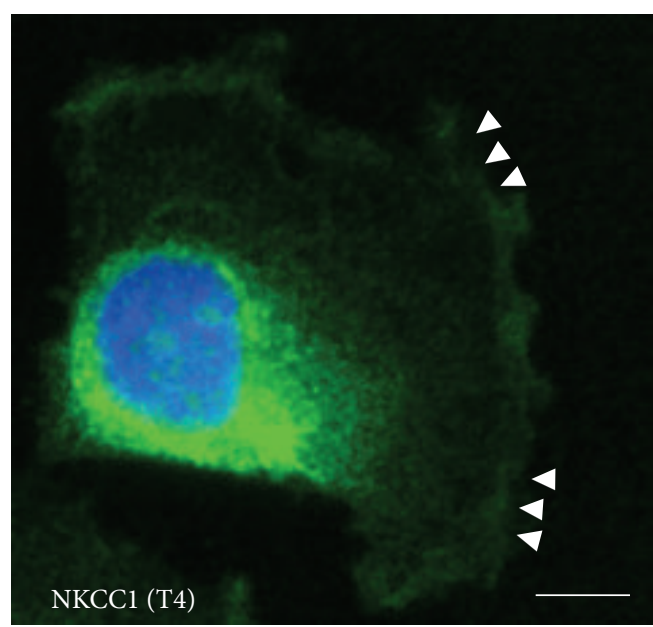

(i)

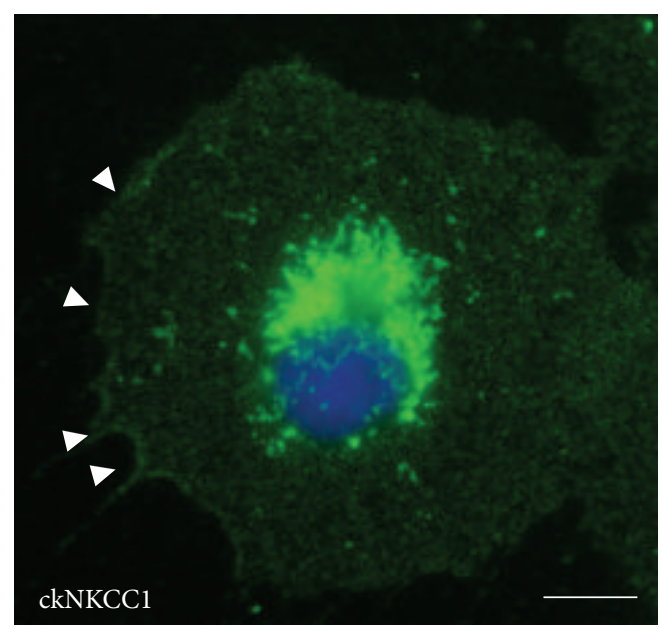

(j)

FIGURE 2: Validation of NKCC1 antibodies in COS7 cells. (a) Representative immunoblot of protein lysates obtained from COS7 cells and developed by using T4 or ckNKCC1. Shown is NKCC1 protein expression detected as two major bands, one of $\sim 130 \mathrm{kDa}$ and another of $\sim 170 \mathrm{kDa}$. ((b)-(c)) Representative immunoblots of liver (b) or kidney (c) tissue extracts from WT or NKCC1 ${ }^{\mathrm{KO}}$ mice, developed by using T4 (b) or ckNKCC1 (c). Shown are bands of predicted MWs corresponding to NKCC1 only in WT tissues. (d) Representative immunoblots of $\mathrm{COS}^{\text {shControl }}$ and $\mathrm{COS}^{\text {shNKCC1 }}$ protein extracts developed by using T4. Shown are bands of predicted MWs corresponding to NKCC1 only in COS7 ${ }^{\text {shControl }}$ cells. ((e)-(h)) Representative images of COS $7^{\text {shNKCC1 }}$ cells stably expressing shRNAs against NKCC1 and GFP as a reporter (e) immunolabeled by using T4 coupled to Cy3-conjugated secondary antibodies (f). Cell nuclei were counterstained with DAPI (g) and the pictures superimposed (h). ((i)-(j)) Immunofluorescence of COS7 cells using T4 (i) or ckNKCC1 (j) coupled to FITC-conjugated secondary antibodies. Arrowheads indicate NKCC1-immunoreactivity at/near the edge of cells. Pictures in (e)-(h) and (i)-(j) were taken at 400x and 600x, respectively. Bar represents $10 \mu \mathrm{m}$.

a quarter of total NKCC1 locates in the plasma membrane. To corroborate this prediction, the immunological presence of $\mathrm{NKCC1}$ was determined in total protein extracts and in biotinylated plasma membrane fractions purified from COS7 cells growing under normal conditions. As shown in Figure 4(a), a small relative proportion of NKCC1 bands of $\sim 130 \mathrm{kDa}$ and $\sim 170 \mathrm{kDa}$ were found in the biotinylated fraction indicating that core/high-mannose and hybrid/complextype N-glycosylated NKCC1 reach the plasma membrane. Of note, the facts that (i) intact cells were biotinylated, collected, lysed, and then affinity-purified with streptavidincoated agarose beads and (ii) cytosolic GAPDH is minimally detected in blots of purified biotinylated fractions all indicate that $\mathrm{NKCC1}$ of $\sim 130 \mathrm{kDa}$ represents plasma membrane located NKCC1 rather than a contamination from potentially biotinylated intracellular compartments. To estimate the relative contribution of these $\mathrm{N}$-glycans to plasma membrane NKCC1, we performed densitometry analysis of immunoblots loaded with equivalent amounts of protein. As shown in Figures 4 (b) and $4(\mathrm{c}), \sim 10 \%$ of total NKCC1 is found in the plasma membrane, mostly corresponding to the core/high-mannose or hybrid forms of the transporter. Therefore, these results suggest that the overall $\mathrm{N}$-glycan nature of $\mathrm{NKCCl}$ does not determine its plasma membrane location.

\subsection{Endogenous NKCC1 Locates in ER, Rab11-Positive Com-} partments, and Medial-Golgi Cisternae. If half of endogenous $\mathrm{NKCC1}$ is core/high-mannose N-glycosylated (Figure 3), then the transporter locates in the endoplasmic reticulum
(ER) in a similar proportion. To determine the immunolocalization pattern of NKCC1 in COS7 cells, we used immunofluorescence microscopy coupled to antibodies directed against calreticulin (CRT), a validated ER marker [41]. As shown in Figures 5(a)-5(c), immunoreactive NKCC1 locates in CRT-positive compartments, confirming ER location of the transporter. To estimate the extent of NKCC1 ER localization, the spatial overlap between NKCC1 (red) and CRT (green) signals in immunofluorescence images was quantified in silico. As shown in Figure 5(d), 50\% of total NKCC1-related signal overlaps with that of CRT, a proportion that correlates the EndoH-sensitive NKCC1 signal obtained in immunoblots (see Figure 3(b)). From the immunofluorescence data presented in Figures 5(a)-5(c), it is evident that NKCC1 also locates in CRT-negative compartments. To visualize the extrareticular component of NKCC1 localization in COS7 cells, ongoing NKCC1 biosynthesis in the ER was inhibited with a $2 \mathrm{~h}$ pulse of cycloheximide (CHX); then, cells were fixed and immunolabeled against CRT. As shown in Figures $5(\mathrm{f})-5(\mathrm{i})$, inhibition of protein synthesis depletes NKCC1 from CRT-positive compartments evidencing a vesicular, post-ER cytoplasmic pattern of $\mathrm{NKCC1}$ expression in these cells.

To identify these additional CRT-negative intracellular compartments, NKCC1 was coimmunolabeled with Rab11, a small GTPase considered a steady-state marker of transGolgi network, secretory granules, constitutive exocytic vesicles, and recycling/sorting endosomes [42, 43]. As shown in Figures 6(a)-6(d), $90 \%$ of endogenous NKCC1 locates in Rabl1-positive compartments consistent with the notion 


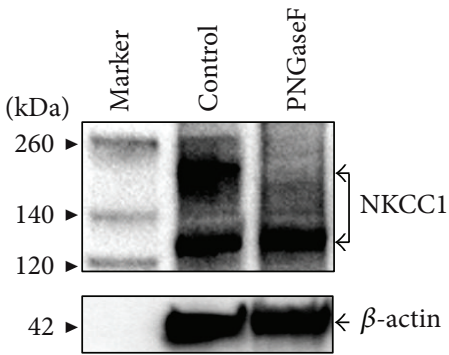

(a)
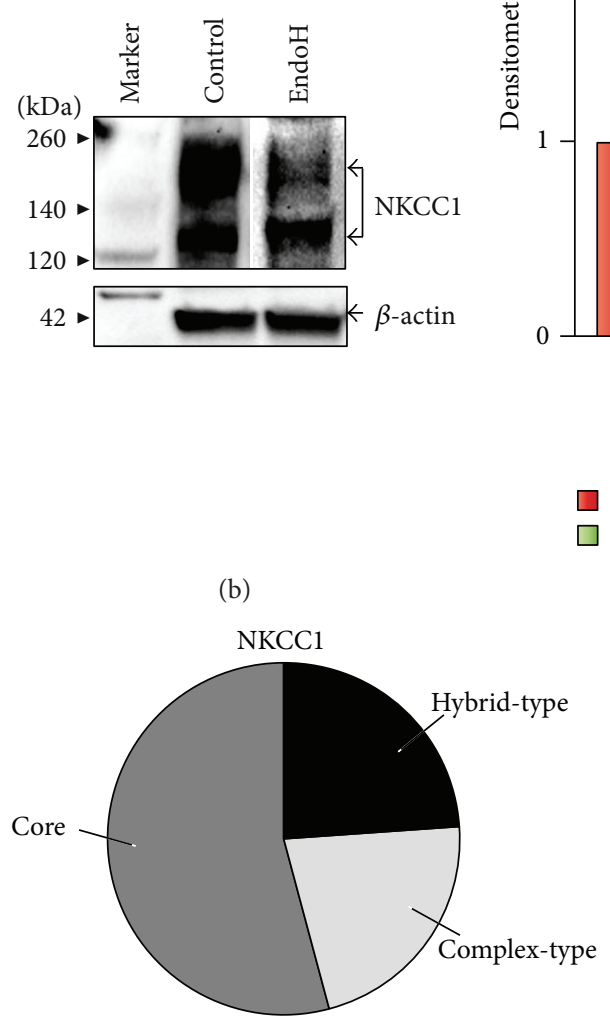

(d)

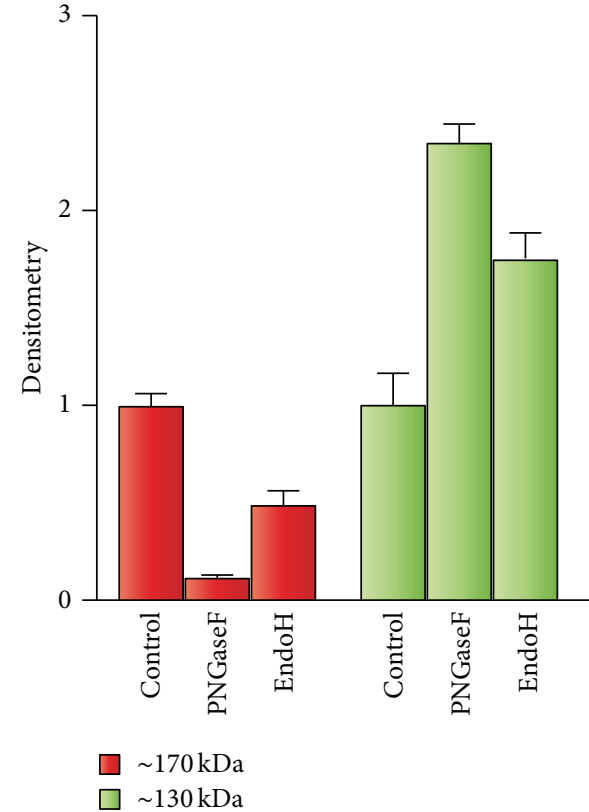

(c)

FIGURE 3: NKCC1 is expressed in COS7 cells as a core/high-mannose, hybrid- and complex-type N-glycosylated protein. ((a)-(b)) Representative immunoblots of protein extracts from COS7 cells grown under basal conditions. Untreated protein extracts (control) or enzymatically digested with PNGaseF (a) or EndoH (b) were immunoblotted and developed using ckNKCC1 coupled to HRP-conjugated secondary antibodies. As loading control, membranes were probed with antibodies against $\beta$-actin. (c) Densitometry analysis of immunoblots of proteins control or treated with PNGaseF or EndoH. Shown are the estimated levels of the two main bands of NKCC1, that is, $\sim 170 \mathrm{kDa}$ (red bars) and $\sim 130 \mathrm{kDa}$ (green bars), before and after enzymatic deglycosylation. Data are expressed as means \pm SEM $(n=5)$. (d) Piechart representing the approximate relative contribution of core/high-mannose, hybrid- and complex-type $\mathrm{N}$-glycans to total endogenous $\mathrm{NKCC1}$ in COS7 cells. Results are calculated based on the percent of increase in the densitometry signal of bands of $\sim 130 \mathrm{kDa}$ after enzymatic treatment.

that NKCC1 is largely confined to the intracellular space. Moreover, these observations indicate that NKCC1 may constitutively traffic between these Rab11-positive compartments including recycling endosomes, ER and Golgi. Therefore, we tested whether NKCC1 is present in Golgi structures. To this end, we used Man2, a marker of cis/medial-Golgi cisternae $[44,45]$. As shown in Figures 7(a)-7(c), NKCC1 appears concentrated in structures immunolabeled with Man2 demonstrating that NKCC1 locates in the cis/medialGolgi. To add support to this conclusion, Golgi cisternae were collapsed into the ER by using brefeldin A (BFA) [46, 47]. As shown in Figures 7(d)-7(f), BFA treatment resulted in redistribution of $\mathrm{NKCC} 1$ and Man2 to the perinuclear region of the cells. Therefore, altogether, these results indicate that the intracellular location of endogenous core/highmannose and hybrid/complex-type N-glycosylated NKCC1 in ER, Rabl1-positive vesicles, and cis/medial-Golgi cisternae reflects its biosynthetic pathway.

3.5. Inhibition of the First Step in N-Glycan Biosynthesis Impairs NKCC1 Expression. To study the role of $\mathrm{N}$ glycosylation on endogenous NKCC1 trafficking and localization, we first treated cells with tunicamycin (TUN, $2 \mu \mathrm{g} / \mathrm{mL}$ for $16 \mathrm{~h}$ ), an inhibitor of the first step of N-glycan biosynthesis. As shown in Figures 8(a) and 8(b), TUN significantly decreases total immunoreactive NKCC1 protein expression levels consistent with the notion that core N-glycosylation of proteins plays a key role in protein stability and quality 

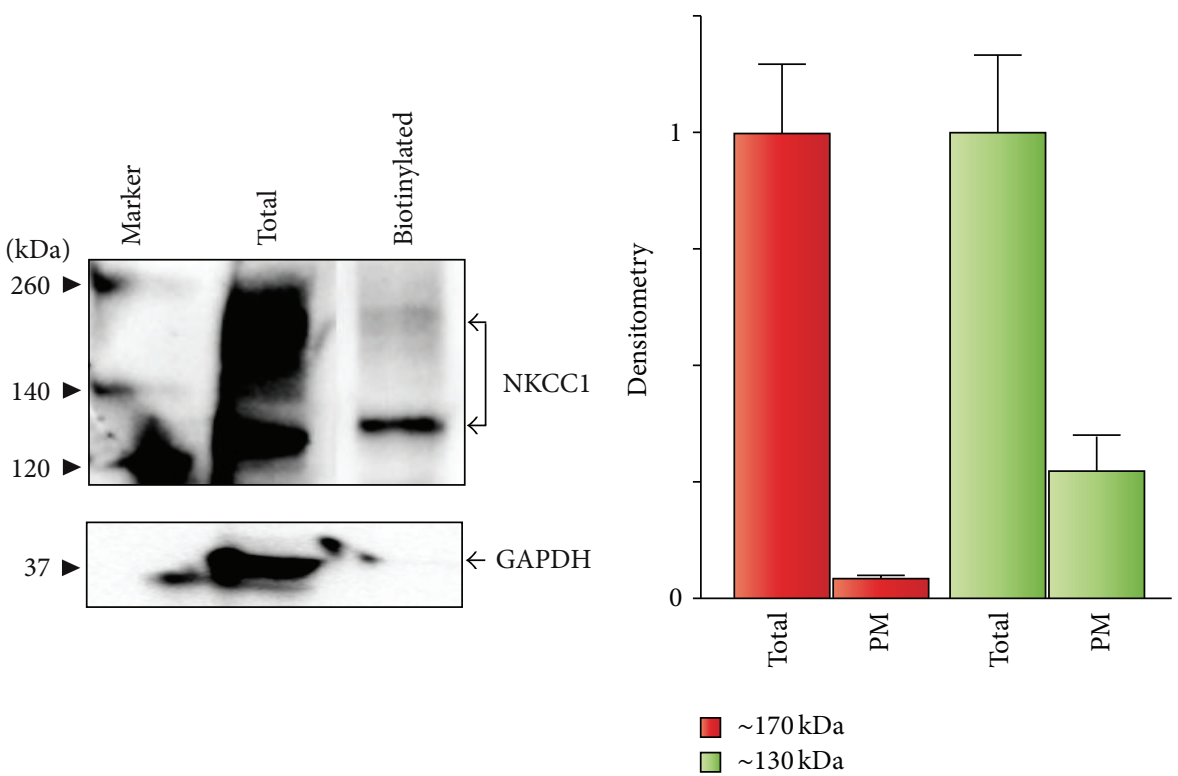

(a)

(b)

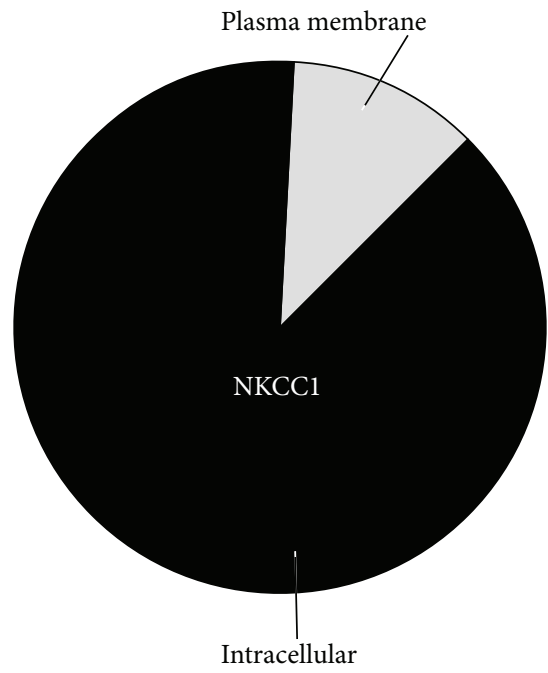

(c)

FIGURE 4: A small proportion of total NKCC1 locates in the plasma membrane. (a) Representative NKCC1 immunoblot of equal amounts of total protein extracts and plasma membrane biotinylated fractions obtained from COS7 cells growing under normal conditions. Shown are bands of expected sizes of $\mathrm{NKCCl}$, that is, $\sim 170 \mathrm{kDa}$ and $\sim 130 \mathrm{kDa}$, in total cellular extracts and in biotinylated plasma membrane fractions. Protein expression of cytosolic GAPDH was used as a loading control for total protein lysates and to assess the purity of biotinylated plasma membrane fractions. (b) Densitometry analysis of immunoblots showing estimated levels of the two main immunobands of NKCC1: core/high-mannose $\sim 130 \mathrm{kDa}$ (green bars) and complex/hybrid $\sim 170 \mathrm{kDa}$ (red bars) in total lysates or biotinylated plasma membrane fractions. Data is expressed as the mean $\pm \operatorname{SEM}(n=3)$. (c) Pie-chart representation of the estimated, relative contribution of total NKCC1 to the plasma membrane.

control in the ER [48-50]. To correlate these results at the plasma membrane level, TUN-treated cells were biotinylated and plasma membrane fractions were purified and subjected to immunoblotting. As shown in Figures 8(c) and 8(d), TUN decreased expression of plasma membrane located NKCC1. Since TUN also decreased total expression levels of NKCC1, as seen in Figures 8(d) and 8(e), these results suggest that the extent of plasma membrane located NKCC1 reflects its biosynthesis levels rather than its N-glycosylation state.
3.6. Complex N-Glycosylation Is Not Required for Plasma Membrane Targeting of NKCC1 but for Its Cotransport Function. Like in the case of NKCC2 engineered to lack consensus $\mathrm{N}$-glycosylation sites [21-26], precluding N-glycosylation with TUN impairs $\mathrm{N}$-glycan maturation and therefore the role of the latter in plasma membrane targeting cannot be addressed with these kinds of experiments. To determine the role of $\mathrm{N}$-glycan maturation in plasma membrane targeting of endogenous NKCC1, cells were treated with kifunensine (KIF, 


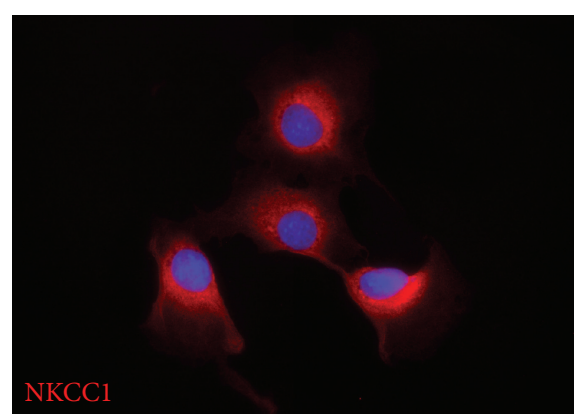

(a)

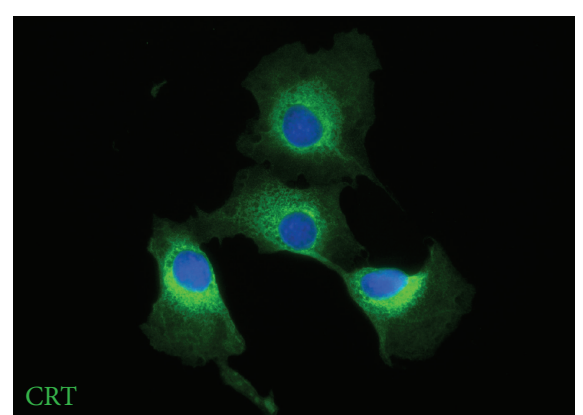

(b)

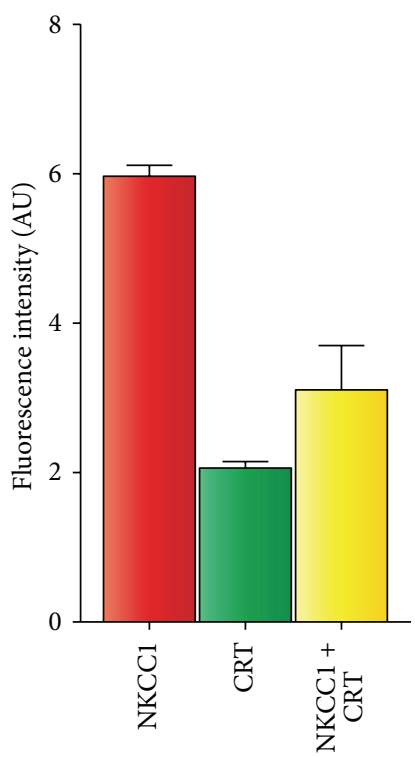

(d)

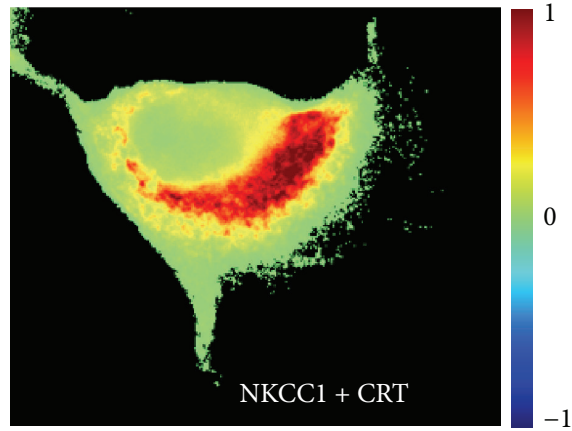

(e)

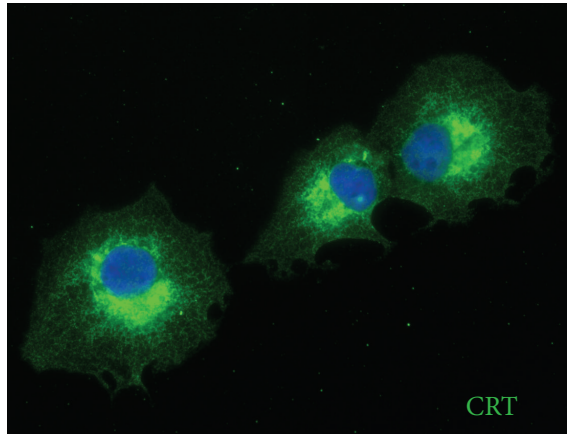

(g)

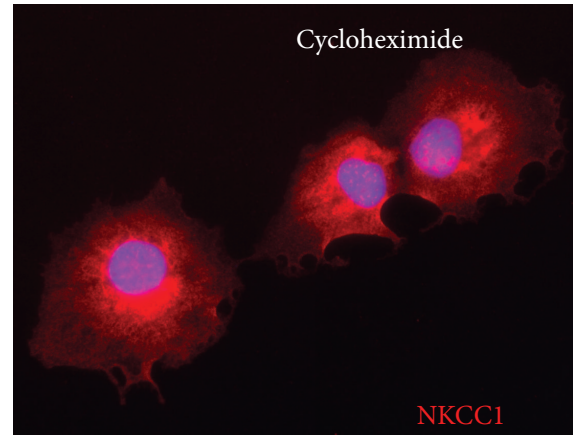

(f)

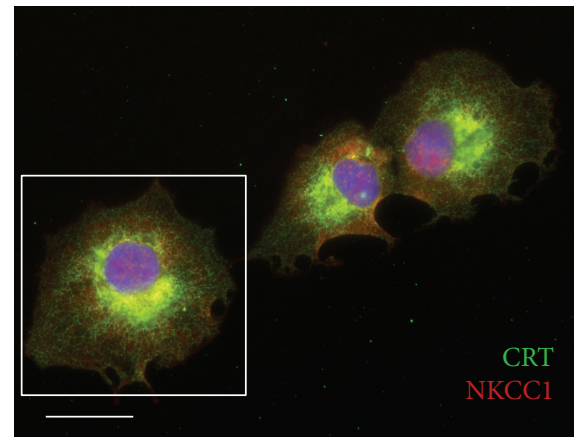

(h)

Figure 5: Continued. 


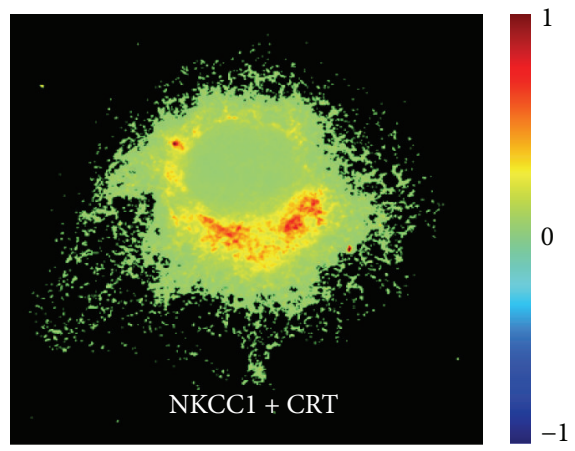

(i)

FIGURE 5: NKCC1 localizes in the ER of COS7 cells. ((a)-(b)) Representative image of COS7 cells immunolabeled against NKCC1 using T4 (a) or calreticulin (CRT, (b)) antibodies and developed using fluorescently labeled secondary antibodies: Cy3 (NKCC1, red) and FITC (CRT, green). (c) Overlay of (a) and (b). Pictures were superimposed to obtain an image where colocalization could be digitally estimated as yellow pixels $($ red + green $=$ yellow). Scale bar represents $10 \mu \mathrm{m}$. (d) Semiquantitation of red, green, and yellow pixels corresponding to NKCC1, CRT, and NKCC1 + CRT, respectively. Shown are the results obtained from at least 10 cells and represented as mean fluorescence intensity in arbitrary units \pm SEM. (e) Colocalization heat-map of the squared cell in (c) computed by using NIH ImageJ. ((f)-(g)) Shown are representative images of COS7 cells grown in the presence of cycloheximide $(1 \mu \mathrm{g} / \mathrm{mL})$ to acutely inhibit protein synthesis and deplete endogenous NKCC1 from the ER. The presence of NKCC1 (f) or CRT (g) was codetected by using the relevant primary antibodies and developed using secondary antibodies labeled with Cy3 (red) or FITC (green) fluorophores. (h) Superimposition of (f) and (g) images to estimate colocalization as heat-maps, as shown in (i).

5-10 $\mu \mathrm{g} / \mathrm{mL})$, an inhibitor of ER-located mannosidase-I and complex N-glycosylation [51-53]. As shown in Figure 9(a), KIF treatment results in increased expression levels of core/high-mannose and hybrid-type N-glycosylated NKCC1 (Figure 9(g), green trace), as expected for inhibition of ERmannosidase-I $[52,54]$. To confirm the hybrid N-glycan nature of KIF-treated NKCC1, protein extracts obtained from KIF-treated COS7 cells were subjected to enzymatic digestion with EndoH. As shown in Figure 9(b), EndoH treatment results in a nearly complete elimination of NKCC1 bands heavier than $\sim 130 \mathrm{kDa}$, indicating that KIF impairs NKCC1 complex N-glycosylation. At the plasma membrane level, KIF treatment did not impact core/high-mannose NKCC1 $(\sim 130 \mathrm{kDa})$ expression levels but resulted in almost undetectable complex N-glycosylated NKCC1 and a parallel increase in the hybrid-type form (Figures 9(c) and 9(h), green trace). Therefore, these results suggest that inhibition of complex-type N-glycosylation does not impact plasma membrane location of NKCC1. To further substantiate these findings, expression of the transporter was determined in COS7 cells treated with swainsonine (SWN, $1-2 \mu \mathrm{g} / \mathrm{mL}$ ), an inhibitor of medial-Golgi Man2, the enzyme involved in the first biosynthetic step of complex N-glycosylation [55, 56]. As shown in Figure 9(d), SWN increases precursor core/high-mannose and hybrid-type N-glycosylated NKCC1 expression (Figure 9(g), red trace), as expected. Further, as shown in Figure 9(e), EndoH digestion of SWN-treated samples resulted in complete elimination of NKCC1 bands higher than $\sim 130 \mathrm{kDa}$, but not in control samples where bands of $\sim 170 \mathrm{kDa}$ complex N-glycosylated, EndoH-resistant $\mathrm{NKCC1}$ proteins are observed suggesting complete inhibition of complex N-glycosylation of NKCC1 by SWN. At the plasma membrane level, SWN also eliminated complex Nglycosylated NKCC1 (Figures 9(f) and 9(h)). However, SWN treatment increased the levels of core/high-mannose and hybrid-type N-glycosylated NKCC1 paralleling the increase in their total expression levels. Together, these results confirm that plasma membrane targeting of $\mathrm{NKCC1}$ is independent of its N-glycosylation state.

To verify that plasma membrane targeted NKCC1 either core/high-mannose, hybrid-type, or complex N-glycosylated is functional, we first determined total NKCC activity in COS7 cells depleted of endogenous $\mathrm{Cl}^{-}$as net $\mathrm{Cl}^{-}$uptake as a function of time. As shown in Figure 9(i), $\mathrm{Cl}^{-}$uptake into COS7 cells reaches a plateau after $\sim 10$ minutes at room temperature and a final extracellular $\left[\mathrm{Cl}^{-}\right]_{0}$ of $139 \mathrm{mM}$. To determine the NKCC-dependent component of $\mathrm{Cl}^{-}$uptake, net $\mathrm{Cl}^{-}$transport into $\mathrm{Cl}^{-}$-depleted cells was determined in the presence of $10 \mu \mathrm{M}$ bumetanide (BTD). This was assessed at saturating concentrations of $\mathrm{Cl}^{-}(139 \mathrm{mM}), 5$ minutes after incubation of $\mathrm{Cl}^{-}$-depleted cells in isotonic (ISO) media. Under these conditions, the BTD-sensitive component of total $\mathrm{Cl}^{-}$uptake reached $\sim 65 \%$ (inset, Figure $9(\mathrm{i})$ ), suggesting that the small proportion of total NKCC1 expressed in the plasma membrane, either core/high-mannose or hybrid- or complex-type, performs functional work. To determine the role of global or complex $\mathrm{N}$-glycosylation on the cotransport function of plasma membrane located NKCC1, cells were incubated in the presence of TUN, KIF, or SWN under conditions comparable to those used for protein expression analyses. As shown in Figure 9(j), total BTD-sensitive $\mathrm{Cl}^{-}$ uptake is almost completely eliminated in COS7 cells treated with TUN, as expected for a drug that heavily reduces total NKCC1 expression levels (see Figure 8). However, treatment of COS7 cells with KIF or SWN which only eliminated complex N-glycosylated NKCC1 at the plasma membrane blocked BTD-sensitive $\mathrm{Cl}^{-}$uptake, suggesting that complex $\mathrm{N}$-glycosylation is required for the transporter to function 


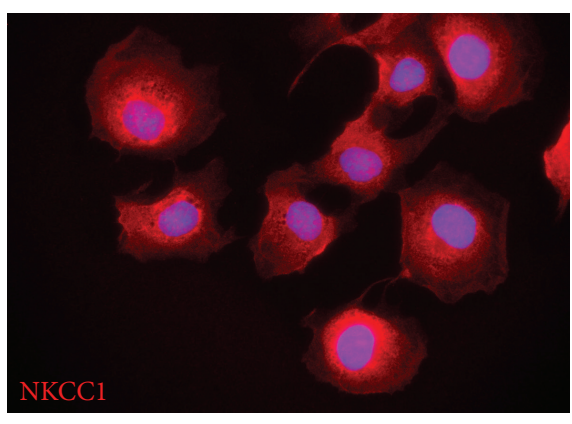

(a)

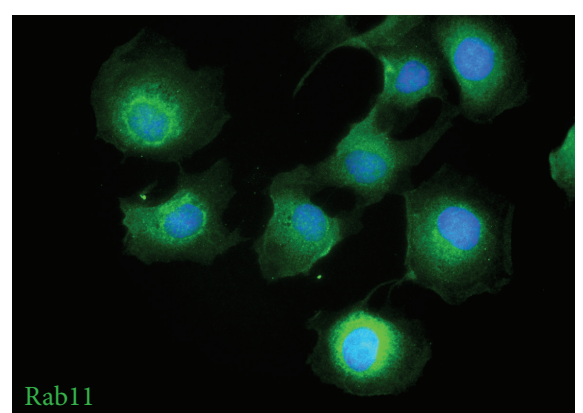

(b)

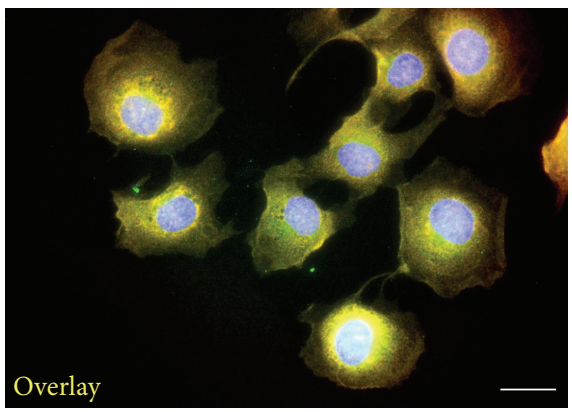

(c)

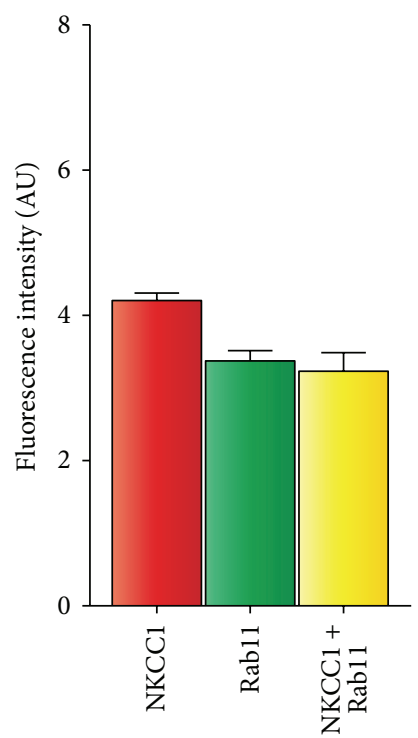

(d)

FIGURE 6: NKCC1 localizes in Rab11-positive compartments in COS7 cells. ((a)-(b)) Shown are representative images of COS7 cells expressing immunoreactive NKCC1 (a) or Rab11 (b). (c) (a) + (b) images superimposed to obtain an overlay image where colocalization could be estimated as yellow pixels (red + green). The scale bar represents $10 \mu \mathrm{m}$. (d) Semiquantitation of red (NKCC1), green (Rabl1), and yellow $(\mathrm{NKCC1}+\mathrm{Rab} 11)$ pixels. Shown are results obtained from at least 10 cells and represented as mean fluorescence intensity in arbitrary units \pm SEM.

and that core/high-mannose or hybrid-type NKCC1 cannot transport $\mathrm{Cl}^{-}$despite their plasma membrane location.

\section{Discussion}

NKCC1 is ubiquitously expressed [57]. However, which NKCC1 splice variants are present in a particular cell model or tissue is frequently unknown. By using RT-PCR, we have provided evidence of NKCCla expression in COS7 cells (Figures 1(b) and 1(c)). A single RT-PCR amplicon was obtained from these cells by using a validated RT-PCR strategy designed to simultaneously coamplify NKCC1 $a$ and NKCC1 $b$ transcripts [27] (Figure 1(c)). In addition, undetectable levels of NKCC1b transcripts in our cell model are supported by the sole presence of nucleotide sequences corresponding to exon 21 in sequencing chromatograms (Figure $1(\mathrm{~d})$ ). Therefore, our results suggest that NKCCla represents most if not all of the total pool of NKCC1 in COS7 cells. Expression of NKCC1 at the protein level in COS7 cells was initially studied using two different antibodies directed against the transporter, that is, T4 and ckNKCC1 (Figure 2). This was performed to validate NKCC1 antibodies in our cell model based on the findings that T4 detects NKCC2, at least when abundantly expressed, as it is the case of the kidney or when forcedly overexpressed in cell models $[40,58]$. Notably, COS7 cells express very low levels of NKCC2 (data not shown). Nevertheless, T4 did not detect NKCC2 in COS7 cells silenced of endogenous $\mathrm{NKCCl}$ or in $\mathrm{NKCC} 1^{\mathrm{KO}}$ tissues indicating that the ability of T4 to cross-react with NKCC2, or any other protein, may depend on its expression levels. Similarly, ckNKCC1 did not detect proteins in immunoblots of kidney extracts obtained from $\mathrm{NKCC}^{\mathrm{KO}}$ mice demonstrating that this antibody does not cross-react with NKCC2 (Figure 2(c)). In addition, our results demonstrate that both $\mathrm{T} 4$ and ckNKCC1 detect similar patterns of NKCC1 expression in all protein samples tested, that is, two bands of $\sim 130$ and $\sim 170 \mathrm{kDa}$, and in fixed cells, that is, intracellular and plasma membrane located NKCC1 (Figures 2(g) and 2(h)). Therefore, these results validate 


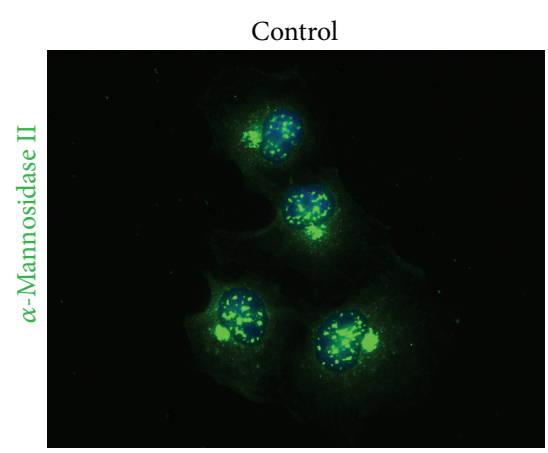

(a)

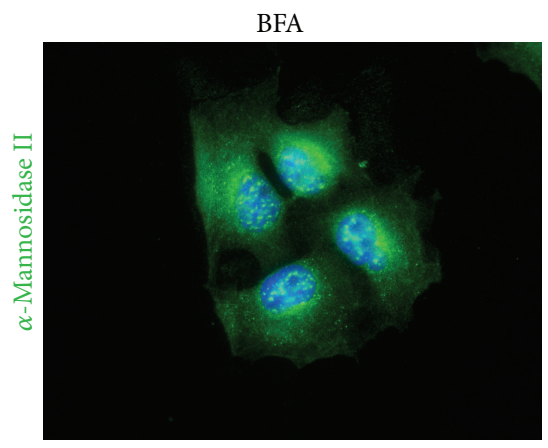

(d)

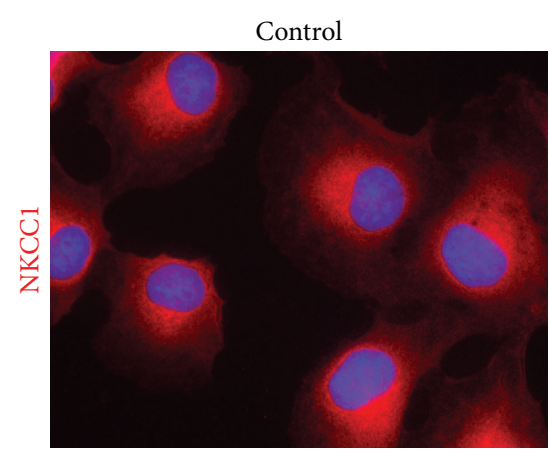

(b)

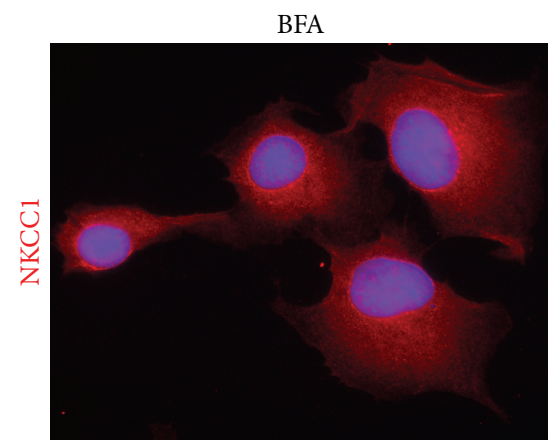

(e)

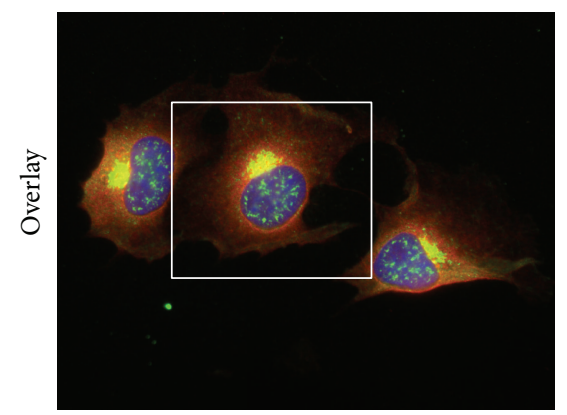

(c)

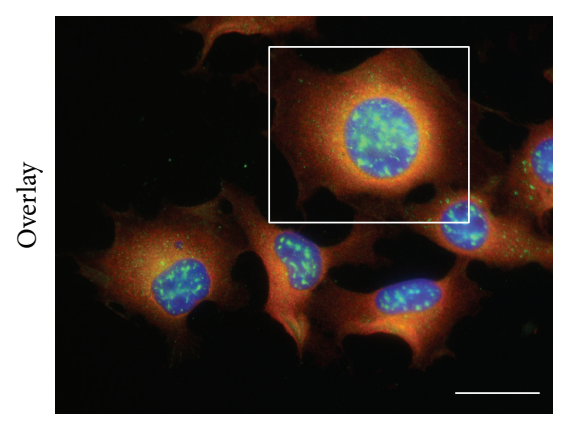

(f)

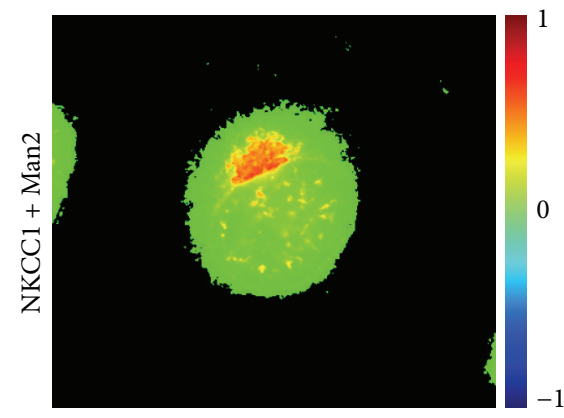

(g)

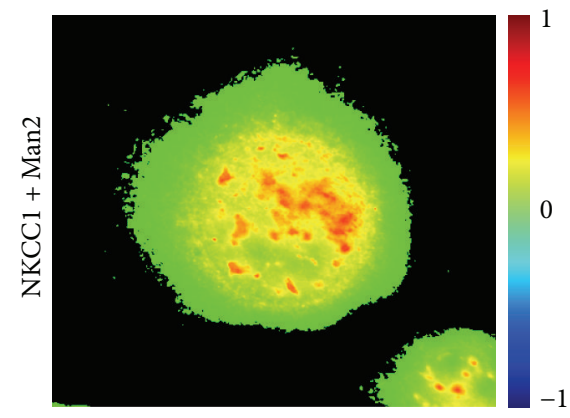

(h)

FiguRE 7: NKCC1 localizes in cis/medial-Golgi cisternae. ((a)-(c)) Shown are representative images of COS7 cells grown under control conditions or treated for $16 \mathrm{~h}$ with $1 \mu \mathrm{g} / \mathrm{mL}$ of brefeldin A (BFA, (d)-(f)). Immunoreactive $\alpha$-mannosidase II (Man2, (a) and (d)) and NKCC1 ((b) and (e)) were detected by using primary antibodies directed against these proteins and developed using secondary antibodies labeled with FITC (green) and Cy3 (red), respectively. ((c) and (f)) Shown are superimposed images to obtain an overlay representing colocalization of NKCC1 and Man2. The scale bar represents $10 \mu \mathrm{m}$. ((g)-(h)) Heat-maps of the squared cells in (c) and (f), respectively, computed by using NIH ImageJ.

the use of these antibodies to study expression, N-glycan composition of NKCC1, and its localization in COS7 cells, the main interests of the present study.

Our results suggest that NKCC1 is expressed in COS7 cells as an $\mathrm{N}$-glycosylated protein (Figures $2-5$ and 9), in agreement with many reports $[21,35-39,59-63]$. However, these reports concluded that NKCC1 is a complex Nglycosylated protein based on digestion experiments using PNGaseF, an amidase that cannot distinguish core/hybrid from complex $\mathrm{N}$-glycans. Our experiments determined the $\mathrm{N}$-glycan nature of NKCC1 in COS7 cells (Figure 3). PNGaseF treatment resulted in an almost complete elimination of the $\sim 170 \mathrm{kDa} \mathrm{N}$-glycan NKCC1 bands, as expected, but also resulted in a concomitant $\sim 2$-fold increase in the band of $\sim 130 \mathrm{kDa}$. The most parsimonious interpretation of these results is that $\sim 50 \%$ of total NKCC1 is hybrid/complex-type $\mathrm{N}$-glycan (Figures 3(c) and 3(d)). In addition, the results after EndoH treatment suggest that approximately half of the total N-glycan load of NKCC1 corresponds to the highmannose/hybrid-type and that only $25 \%$ is of the complex nature that is resistant to the action of EndoH (Figures 3(c) and 3(d)). These data are consistent with the interpretation that endogenous NKCC1 is expressed in COS7 cells as core/high-mannose and hybrid/complex N-glycosylated in an approximate 1:1 ratio, far less than that observed when NKCC1 was overexpressed in mammalian cells $[16,21]$. 


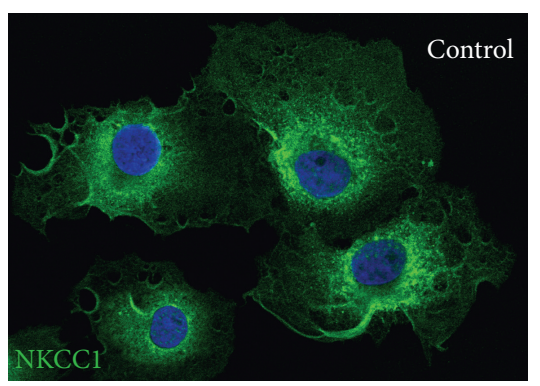

(a)

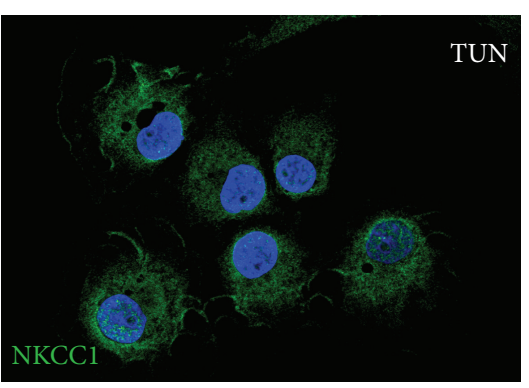

(b)

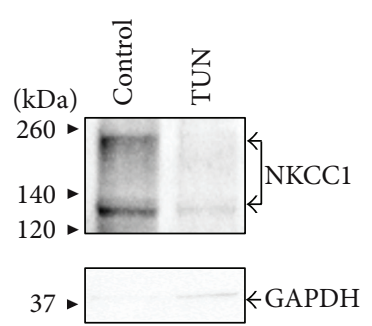

(c)

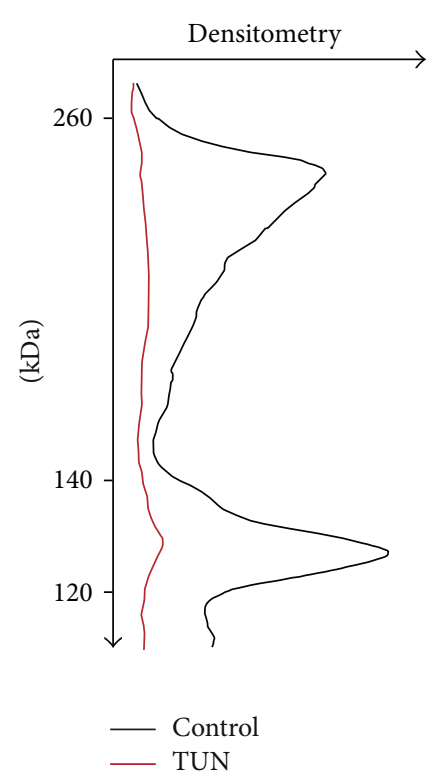

(d)

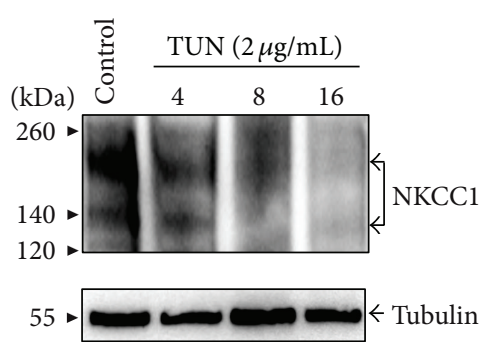

(e)

Figure 8: The first step of N-glycan biosynthesis is required for NKCC1 protein expression. ((a)-(b)) Shown are representative immunofluorescence microscopy images of COS7 cells grown under control conditions (a) or treated for $16 \mathrm{~h}$ with $2 \mu \mathrm{g} / \mathrm{mL}$ tunicamycin (TUN, (b)). NKCC1 immunolocalization was analyzed with T4 and FITC-labeled secondary antibodies (green). (c) Representative immunoblot with ckNKCC1 demonstrating expression of NKCC1 in the biotinylated plasma membrane fraction purified from COS7 cells control or treated with TUN. Protein expression of cytosolic GAPDH was used to assess the purity of biotinylated plasma membrane fractions. (d) Densitometry scanning of the immunoblot in (c) representing the extent to which TUN (red trace) decreases plasma membrane located NKCC1 (black trace). (e) Representative immunoblot showing the expression pattern of total NKCC1 in COS7 cells in response to TUN $2 \mu \mathrm{g} / \mathrm{mL}$ during the indicated periods of time. As loading control, immunoblots were probed against tubulin.

These differences in NKCC1 behavior when endogenously expressed or when its expression is forced in cell lines are not out of the ordinary; enzymatic N-glycan biosynthesis depends on the level and transit of substrate proteins en route to their destination [45]. Therefore, it is expected that the proportion of complex N-glycosylated NKCC1 expressed at a given time may be variable and dependent upon the precursor protein reaching the appropriate N-glycosylation machinery to reach a given degree of $\mathrm{N}$-glycan elaboration and decoration to be considered complex N-glycosylated, a task easily achieved when NKCCs are overexpressed $[16,26]$.

The prevailing consensus indicates that complex $\mathrm{N}$ glycosylation is necessary for NKCCs to leave Golgi cisternae for plasma membrane delivery [16, 21, 64]. Among the many molecular signals potentially involved in plasma membrane targeting of NKCC1, N-glycosylation has indeed been assumed to be one of them. Our experiments revealed the presence of low levels of potentially complex N-glycosylated NKCC1 $(\sim 170 \mathrm{kDa})$ at the plasma membrane and much higher levels of core/high-mannose NKCC1 ( 130 kDa) (Figure 4 ). In fact, $\sim 10 \%$ of total NKCC1 was roughly estimated at the plasma membrane under basal conditions (Figures 4(a)-4(c)), mostly of the core/high-mannose N-glycan type. Although the proportion of total $\mathrm{NKCCl}$ in the plasma membrane estimated in our experiments is well within the ranges recently reported for other transporters including the $\mathrm{Na}^{+} / \mathrm{H}^{+}$exchanger-3 (NHE3) [65], several members of the Slc26a family of transporters [66], or channels such as CFTR [67], the possibility of contamination with intracellular $\mathrm{NKCC1}$ as the source of $\sim 130 \mathrm{kDa}$ core/high-mannose $\mathrm{N}$ glycosylated transporters in the plasma membrane may still remain. However, GAPDH, an abundant cytoplasmic protein expressed in all cells, was minimally detected, if any, in biotinylated preparations (see Figures 4(a), 8(c), 9(c), and 


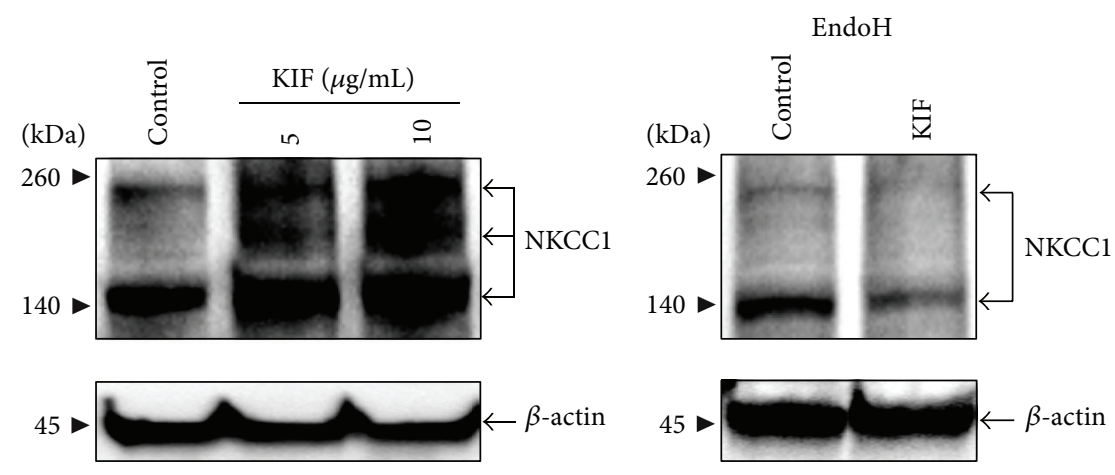

(a)

(b)

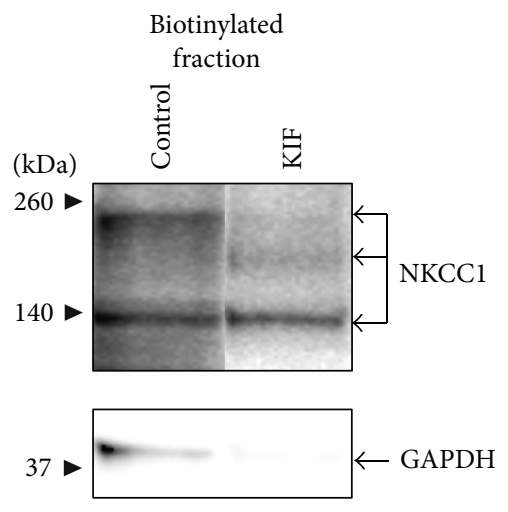

(c)

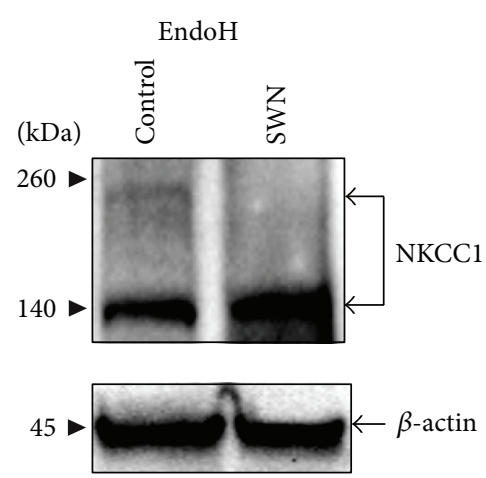

(e)

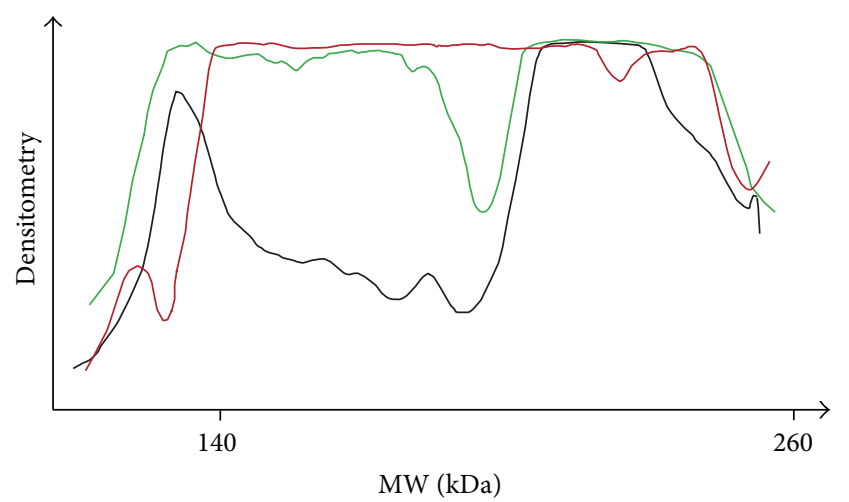

- Control

KIF

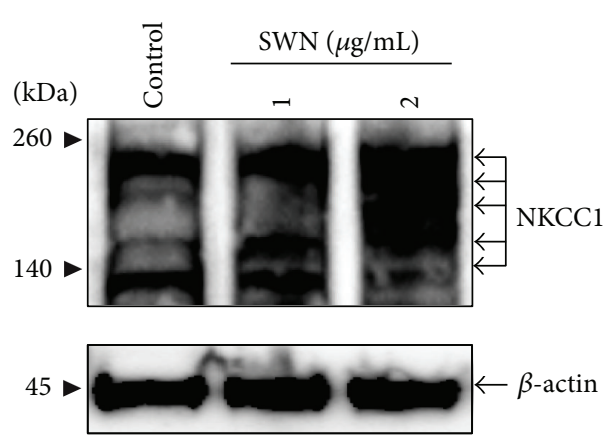

(d)

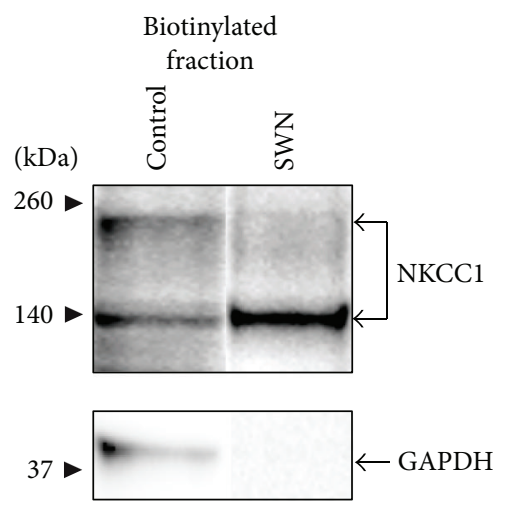

(f)

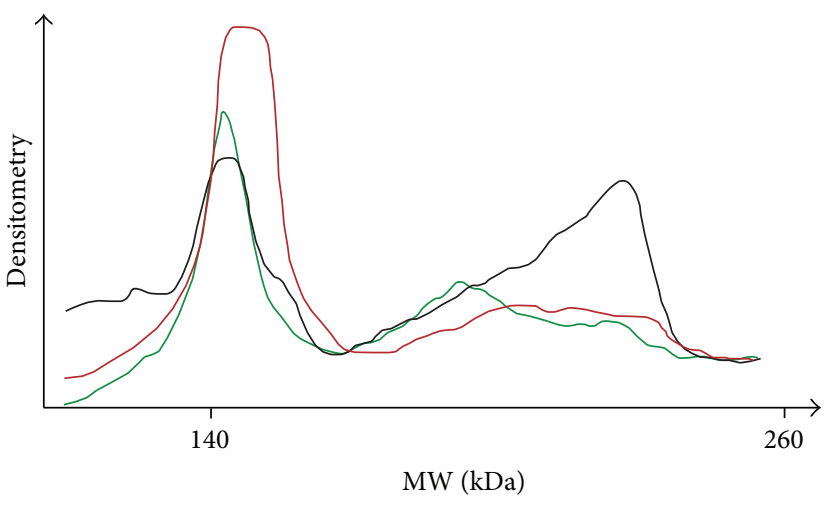

- Control
KIF

(g)

(h)

Figure 9: Continued. 


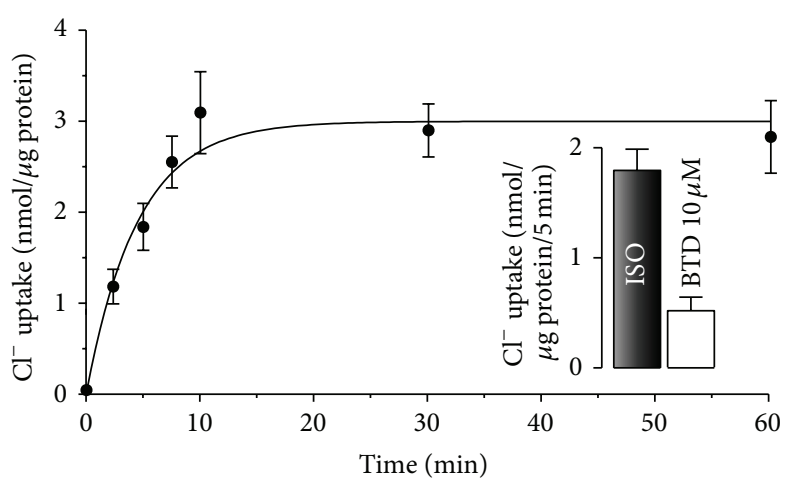

(i)

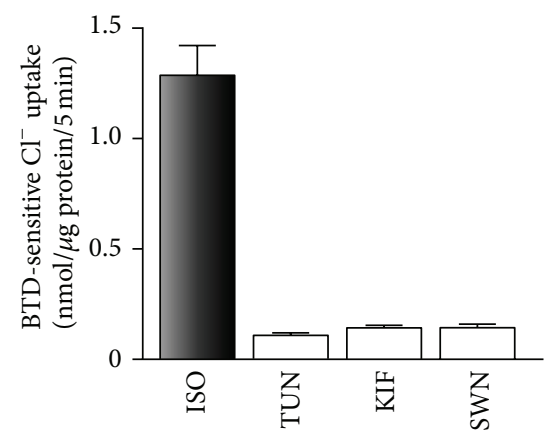

$(\mathrm{j})$

FIGURE 9: Inhibition of N-glycan processing or complex N-glycosylation does not preclude NKCC1 plasma membrane localization but impairs its function. ((a) and (d)) Shown are representative immunoblots experiments showing total endogenous expression levels of NKCC1 $a$ in COS7 cells incubated with (DMSO, control) $5-10 \mu \mathrm{g} / \mathrm{mL}$ of kifunensine (KIF, (a)) or 1-2 $\mu \mathrm{g} / \mathrm{mL}$ swainsonine (SWN, (d)) for $16 \mathrm{~h}$. Note that the expected bands of NKCCla, that is, $\sim 130 \mathrm{kDa}$ and $\sim 170 \mathrm{kDa}$, are detected in control and treated cells whereas additional ckNKCCl-immunoreactive bands centered at $\sim 150 \mathrm{kDa}$ are observed only in protein extracts from KIF/SWN-treated cells. As loading control, immunoblots were developed using antibodies directed against $\beta$-actin. ((b) and (e)) Shown are representative immunoblots demonstrating expression of EndoH-sensitive hybrid-type N-glycosylated NKCCla in total protein extracts of COS7 cells treated for 16 hs with KIF $(10 \mu \mathrm{g} / \mathrm{mL})$ or SWN $(2 \mu \mathrm{g} / \mathrm{mL})$. Note the absence of immunoreactive bands corresponding to NKCC1 $a \sim 170 \mathrm{kDa}$ in cell extracts obtained from KIF/SWN-treated cells. ((c) and (f)) Shown are representative immunoblots demonstrating expression of NKCCla in biotinylated plasma membrane fractions of COS7 cells grown under control conditions or treated for $16 \mathrm{~h}$ with KIF or SWN. Protein expression of the cytosolic GAPDH was used to assess the purity of the plasma membrane fractions. (g) Densitometry scanning representing the total cellular N-glycan types of NKCC1 in COS7 cells control or treated for $16 \mathrm{~h}$ with KIF $(10 \mu \mathrm{g} / \mathrm{mL})$ or SWN $(2 \mu \mathrm{g} / \mathrm{mL})$. (h) Representative densitometry scanning of NKCC1 immunoblots of plasma membrane fractions obtained from COS7 cells control or treated for $16 \mathrm{~h}$ with $\mathrm{KIF}(10 \mu \mathrm{g} / \mathrm{mL})$ or SWN $(2 \mu \mathrm{g} / \mathrm{mL})$. (i) $\mathrm{Cl}^{-}$uptake into COS7 cells depleted of endogenous $\mathrm{Cl}^{-}$as a function of time (0-60 min). Uptake is represented as nmol/ $\mu \mathrm{g}$ protein $[$ mean $\pm \operatorname{SEM}(n=6)]$. Inset: mean $\mathrm{Cl}^{-}$uptake $[\mathrm{nmol} / \mu \mathrm{g}$ protein $/ 5 \mathrm{~min} \pm \mathrm{SEM}(n=5)]$ obtained under isotonic conditions (ISO, black bar) or in the presence of BTD $10 \mu \mathrm{M}$ (ISO + BTD, white bar). (j) Impact of TUN $(2 \mu \mathrm{g} / \mathrm{mL}), \mathrm{KIF}(10 \mu \mathrm{g} / \mathrm{mL}), \mathrm{or} \mathrm{SWN}(1 \mu \mathrm{g} / \mathrm{mL})$ treatment (16 hs) on the BTD-sensitive component of $\mathrm{Cl}^{-}$uptake into COS7 cells. Results are expressed as nmol/ $\mu \mathrm{g}$ protein $/ 5 \mathrm{~min} \pm \mathrm{SEM}(n=3)$.

9(f)). Furthermore, the presence of "nonprocessed" NKCC1 in the plasma membrane of cells should not be surprising when the concept is placed within the context of recently published evidence. For instance, core/high-mannose and hybrid/complex-type Slc12a5 (KCC2) and Slc12a6 (KCC3) do reach the plasma membrane of oocytes overexpressing these proteins [68] and both $130 \mathrm{kDa}$ and $170 \mathrm{kDa}$ NKCC1 have been detected in membrane fractions of spinal cord neurons [69]. In addition, Slc26a1 is found in the plasma membrane as complex and high-mannose N-glycans, whereas Slc26a4 traffics to the plasma membrane fully deglycosylated [66], in analogy to Slc4al, which is also found at the plasma membrane fully deglycosylated [70]. Therefore, when taken together, our results are compatible with the hypothesis that plasma membrane location of $\mathrm{NKCC1}$ does not depend on the $\mathrm{N}$-glycan nature of the transporter and, therefore, NKCC1 plasma membrane location may reflect its biosynthetic levels.

As any protein with predicted transmembrane domains, $\mathrm{NKCC} 1$ is intuitively expected to be present, to some extent, in membrane compartments including ER, Golgi cisternae, endosomes, and lysosomes. Except for the latter, where we could not find clear immunological evidence of NKCC1 localization (data not shown), the transporter was found in CRT-, Rab11-, and Man2-positive compartments (Figures 5-7). Further, approximately half of endogenous NKCC1 localized in the ER (Figure 5), a finding in line with the observation that $\sim 50 \%$ of endogenous NKCC1 is core/highmannose N-glycosylated (Figures 3(c) and 3(d)) and with the fact that core/high-mannose N-glycan proteins are invariably biosynthesized in the ER [49]. However, not all immunoreactive NKCC1 was found in ER. In fact, depleting NKCC1 from ER with cycloheximide resulted in the dispersion of NKCC1 into nonreticular compartments morphologically assessed as small vesicles suffused throughout the cytoplasm or condensed as rings around nuclei (Figures 5(f)-5(i)). This fine vesicular distribution of NKCCl in COS7 cells is typical of the recycling endosome compartment [47]. In line, NKCC1 and Rab11, an endosome marker, colocalized (Figure 6). Furthermore, since complex N-glycosylation of proteins commences in the medial-Golgi, it follows that some proportion of total endogenous NKCCl must be found in this organelle. Our results suggest colocalization of endogenous NKCC1 and Man2 (Figure 7), a cis/medial-Golgi resident enzyme [56]. However, whether this step is necessary for plasma membrane targeting of the transporter is debatable. Our results showed that TUN, a potent inhibitor of the first step of $\mathrm{N}$-glycan biosynthesis, significantly reduced total NKCC1 protein levels (Figure 8), supporting the hypothesis that core N-glycosylation is important for NKCC1 biosynthesis and therefore trafficking. Indeed, the TUN-mediated decrease in total NKCC1 expression paralleled the reduced levels of $\mathrm{NKCCl}$ expression at the plasma membrane (Figures 
$8(\mathrm{c})$ and $8(\mathrm{~d})$ ), a finding compatible with the notion that plasma membrane availability of the transporter depends on its biosynthetic levels (Figure 8(e)) rather than its Nglycan state, because proteins that cannot be $\mathrm{N}$-glycosylated cannot mature and are frequently degraded. Therefore, the role of $\mathrm{N}$-glycan maturation on plasma membrane targeting cannot be directly addressed by using TUN. Accordngly, we used KIF, an ER-mannosidase-I inhibitor, which precludes Nglycan maturation without impacting protein stability. Our results demonstrated that KIF increased total expression of EndoH-sensitive, core/high-mannose, and hybrid-type N-glycosylated NKCC1 (Figures 9(a), 9(b), and 9(g)), as expected for impaired mannose trimming in the ER [52, 54]. Interestingly, KIF increased the levels of hybrid-type Nglycan NKCCl in the plasma membrane (Figures 9(c) and 9(h)) supporting the notion that NKCCl of any N-glycan nature may reach that compartment. However, complex Nglycosylation also depends on demannosylated N-glycan substrates in the medial-Golgi. Therefore, KIF cannot exclude the possibility of a potential involvement of complex Nglycosylation in plasma membrane sorting. We addressed this issue by blocking Man2, the enzyme responsible of the first step of complex N-glycan biosynthesis. Our results demonstrate that SWN eliminated NKCC1 complex N-glycosylation and increased total and plasma membrane located core/highmannose and hybrid-type N-glycosylated NKCC1 (Figures 9(d)-9(h)) suggesting that NKCC1 expression levels (of any $\mathrm{N}$-glycan nature) parallel the levels of transporter in the plasma membrane and, therefore, plasma membrane located $\mathrm{NKCC1}$ reflects its biosynthesis.

It has been suggested that $\mathrm{N}$-glycosylation of membrane transporters of the Slc12a family plays an important role in their functional activity [23-26, 71, 72]. Interestingly, sitedirected mutagenesis of the two $\mathrm{N}$-glycan sequons present in rat Slc12a3 almost abolished NCC-mediated cotransport without eliminating plasma membrane expression in X. laevis oocytes [71] whereas elimination of N-glycan sequons in the flounder Slc12a3 or rat Slc12a1 reduced both surface expression and total transport activity by $50 \%[22,73]$ suggesting that $\mathrm{N}$-glycosylation is important for either plasma membrane targeting, cotransport function, or both. Our results suggest that COS7 cells upload $\mathrm{Cl}^{-}$in a BTD-sensitive manner (Figure 9(i)) indicating that plasma membrane located NKCC1, either core/high-mannose, hybrid-, complex-type $\mathrm{N}$-glycosylated, or a combination, thereof does transport $\mathrm{Cl}^{-}$. These findings support at least three hypotheses: (i) NKCC1 function is represented by the core/high-mannose type, the most abundant form of the transporter in the plasma membrane of COS7 cells (Figure 4(a)), (ii) all N-glycan species of NKCCl, that is, core/hybrid- and complex-type, are active, and (iii) core/high-mannose/hybrid NKCCl are transport-deficient and, therefore, complex $\mathrm{N}$-glycosylated NKCC1 represents the functional pool of the transporter. Our results support the latter case because treatment of COS7 cells with KIF or SWN, which eliminated complex Nglycosylated NKCC1 from the plasma membrane, also abolished BTD-dependent $\mathrm{Cl}^{-}$uptake (Figure 9(j)), suggesting that core/high-mannose-type NKCCl does not support $\mathrm{Cl}^{-}$ uptake despite its presence in the plasma membrane relative to complex N-glycosylated NKCCl, which may represent the active form of the transporter.

\section{Conclusions}

We have presented evidence for a key role of complex Nglycosylation in the cotransport function of NKCCl but not for its targeting to the plasma membrane. In fact, the degree of NKCCl targeting to this compartment may depend on its biosynthetic levels rather than the degree of attainable complex N-glycosylation. These conclusions, together with the fact that endogenous NKCC1 is also present in intracellular compartments of many cell types, have potential ramifications, particularly within functional interpretation of results, as most of plasma membrane located NKCC1 appears unable to upload $\mathrm{Cl}^{-}$into the cell whereas a small proportion of plasma membrane NKCC1, which is complex $\mathrm{N}$-glycosylated, may represent the functionally active pool of the transporter. Further, our results raise the possibility that intracellular $\mathrm{Cl}^{-}$regulation and the cellular functions that depend on $\left[\mathrm{Cl}^{-}\right]_{\mathrm{i}}$ (e.g., GABAergic signaling, cell volume, neuropeptide, or hormone release) may be sensitive to ER stress or nutrient availability. In addition, it remains open the possibility that core/hybrid-type NKCC1 located in the plasma membrane may have a role in cell physiology independently of its transport function.

\section{Conflict of Interests}

The authors declare that they have no competing interests.

\section{Authors' Contribution}

Richa Singh carried out protein expression, deglycosylation, and immunolocalization experiments and their densitometry/morphometry analyses and drafted the first version of the paper. Mohammed Mashari Almutairi carried out $\mathrm{Cl}^{-}$ uptake experiments. Romario Pacheco-Andrade performed antibody characterization experiments. Mohamed Y. Mahmoud Almiahuob produced and maintained cells lacking NKCC1 and Mauricio Di Fulvio performed mRNA expression analyses, conceived the studies, and wrote the paper. All authors participated in the conception and experimental design and in the analysis and interpretation of data and revised the paper for important intellectual content before giving final approval.

\section{Acknowledgments}

The authors are grateful to Drs. Norma Adragna, Peter Lauf, Javier Alvarez-Leefmans, and Dan Halm for their discussions and thoughtful suggestions. Special thanks go to Pavany Beesety for the preparation of control constructs for transfection. This work was financially supported in part by funds from the American Diabetes Association, the Diabetes Action Research and Education Foundation, and the Boonshoft School of Medicine (BSoM), Wright State University 
(WSU) Seed Grant Program. MMA was supported by scholarships from King Saud University (Riyadh, Saudi Arabia). RP-A was supported by the US-Brazil Higher Education Consortia Program FIPSE/CAPES Exchange scholarship.

\section{References}

[1] A.-M. Hartmann, D. Tesch, H. G. Nothwang, and O. R. P. Bininda-Emonds, "Evolution of the cation chloride cotransporter family: ancient origins, gene losses, and subfunctionalization through duplication," Molecular Biology and Evolution, vol. 31, no. 2, pp. 434-447, 2014.

[2] F. Alvarez-Leefmans, "Intracellular chloride regulation," in Cell Physiology Sourcebook: Essentials of Membrane Biophysics, Elsevier/AP, Boston, Mass, USA, 4th edition, 2012.

[3] G. Gamba, "Molecular physiology and pathophysiology of electroneutral cation-chloride cotransporters," Physiological Reviews, vol. 85, no. 2, pp. 423-493, 2005.

[4] M. Di Fulvio, P. D. Brown, and L. Aguilar-Bryan, "Chloride channels and transporters in $\beta$-cell physiology," in The Islets of Langerhans, M. S. Islam, Ed., vol. 1, pp. 401-451, Springer, Berlin, Germany, 2nd edition, 2014.

[5] A.-M. Hartmann and H. G. Nothwang, "Molecular and evolutionary insights into the structural organization of cation chloride cotransporters," Frontiers in Cellular Neuroscience, vol. 8, article 470, 2015.

[6] J. Randall, T. Thorne, and E. Delpire, "Partial cloning and characterization of Slc12a2: the gene encoding the secretory $\mathrm{Na}^{+}$$\mathrm{K}^{+}-2 \mathrm{Cl}^{-}$cotransporter," The American Journal of Physiology, vol. 273, no. 4, pp. C1267-C1277, 1997.

[7] C. R. T. Vibat, M. J. Holland, J. J. Kang, L. K. Putney, and M. E. O’Donnell, “Quantitation of $\mathrm{Na}^{+}-\mathrm{K}^{+}-2 \mathrm{Cl}^{-}$cotransport splice variants in human tissues using kinetic polymerase chain reaction," Analytical Biochemistry, vol. 298, no. 2, pp. 218-230, 2001.

[8] M. R. Kaplan, M. D. Plotkin, D. Brown, S. C. Hebert, and E. Delpire, "Expression of the mouse $\mathrm{Na}-\mathrm{K}-2 \mathrm{Cl}$ cotransporter, mBSC2, in the terminal inner medullary collecting duct, the glomerular and extraglomerular mesangium, and the glomerular afferent arteriole," The Journal of Clinical Investigation, vol. 98, no. 3, pp. 723-730, 1996.

[9] A. Majid, T. Speake, L. Best, and P. D. Brown, "Expression of the $\mathrm{Na}^{+}-\mathrm{K}^{+}-2 \mathrm{Cl}^{-}$cotransporter in $\alpha$ and $\beta$ cells isolated from the rat pancreas," Pflugers Archiv European Journal of Physiology, vol. 442, no. 4, pp. 570-576, 2001.

[10] S. Alshahrani, F. J. Alvarez-Leefmans, and M. Di Fulvio, "Expression of the Slc12a1 gene in pancreatic $\beta$-cells: molecular characterization and in silico analysis," Cellular Physiology and Biochemistry, vol. 30, no. 1, pp. 95-112, 2012.

[11] E. K. Hoffmann, I. H. Lambert, and S. F. Pedersen, "Physiology of cell volume regulation in vertebrates," Physiological Reviews, vol. 89, no. 1, pp. 193-277, 2009.

[12] L. N. Nejsum, J. Praetorius, and S. Nielsen, "NKCC1 and NHE1 are abundantly expressed in the basolateral plasma membrane of secretory coil cells in rat, mouse, and human sweat glands," The American Journal of Physiology - Cell Physiology, vol. 289, no. 2, pp. C333-C340, 2005.

[13] B. Walcott, A. Birzgalis, L. C. Moore, and P. R. Brink, "Fluid secretion and the $\mathrm{Na}^{+}-\mathrm{K}+-2 \mathrm{Cl}^{-}$cotransporter in mouse exorbital lacrimal gland," The American Journal of Physiology-Cell Physiology, vol. 289, no. 4, pp. C860-C867, 2005.
[14] J. M. Shillingford, K. Miyoshi, M. Flagella, G. E. Shull, and L. Hennighausen, "Mouse mammary epithelial cells express the $\mathrm{Na}-\mathrm{K}-\mathrm{Cl}$ cotransporter, NKCC1: characterization, localization, and involvement in ductal development and morphogenesis," Molecular Endocrinology, vol. 16, no. 6, pp. 1309-1321, 2002.

[15] R. L. Jakab, A. M. Collaco, and N. A. Ameen, "Physiological relevance of cell-specific distribution patterns of CFTR, NKCC1, NBCe1, and NHE3 along the crypt-villus axis in the intestine," The American Journal of Physiology-Gastrointestinal and Liver Physiology, vol. 300, no. 1, pp. G82-G98, 2011.

[16] J. A. Payne, C. Ferrell, and C. Y. Chung, "Endogenous and exogenous $\mathrm{Na}-\mathrm{K}-\mathrm{Cl}$ cotransporter expression in a low $\mathrm{K}$ resistant mutant MDCK cell line," The American Journal of Physiology-Cell Physiology, vol. 280, no. 6, pp. C1607-C1615, 2001.

[17] I. C. Del Castillo, M. Fedor-Chaiken, J. C. Song et al., "Dynamic regulation of $\mathrm{Na}^{+}-\mathrm{K}^{+}-2 \mathrm{Cl}^{-}$cotransporter surface expression by PKC-E in $\mathrm{Cl}^{-}$-secretory epithelia," The American Journal of Physiology-Cell Physiology, vol. 289, no. 5, pp. C1332-C1342, 2005.

[18] P. G. Bouyer, X. Tang, C. R. Weber, L. Shen, J. R. Turner, and J. B. Matthews, "Capsaicin induces NKCC1 internalization and inhibits chloride secretion in colonic epithelial cells independently of TRPV1," The American Journal of PhysiologyGastrointestinal and Liver Physiology, vol. 304, no. 2, pp. G142G156, 2013.

[19] G. Su, R. A. Haworth, R. J. Dempsey, and D. Sun, "Regulation of $\mathrm{Na}^{+}-\mathrm{K}^{+}-\mathrm{Cl}^{-}$cotransporter in primary astrocytes by dibutyryl cAMP and high $\left[\mathrm{K}^{+}\right]_{o}$," The American Journal of PhysiologyCell Physiology, vol. 279, no. 6, pp. C1710-C1721, 2000.

[20] S. Alshahrani and M. Di Fulvio, "Enhanced insulin secretion and improved glucose tolerance in mice with homozygous inactivation of the $\mathrm{Na}^{+} \mathrm{K}^{+} 2 \mathrm{Cl}^{-}$co-transporter 1," Journal of Endocrinology, vol. 215, no. 1, pp. 59-70, 2012.

[21] A. Nezu, M. N. Parvin, and R. J. Turner, "A conserved hydrophobic tetrad near the $\mathrm{C}$ terminus of the secretory $\mathrm{Na}^{+}-\mathrm{K}^{+}-2 \mathrm{Cl}^{-}$ cotransporter (NKCC1) is required for its correct intracellular processing," The Journal of Biological Chemistry, vol. 284, no. 11, pp. 6869-6876, 2009.

[22] A. Paredes, C. Plata, M. Rivera et al., "Activity of the renal $\mathrm{Na}^{+}-\mathrm{K}+-2 \mathrm{Cl}^{-}$cotransporter is reduced by mutagenesis of $\mathrm{N}-$ glycosylation sites: Role for protein surface charge in Cl- transport," The American Journal of Physiology-Renal Physiology, vol. 290, no. 5, pp. F1094-F1102, 2006.

[23] B. Benziane, S. Demaretz, N. Defontaine et al., "NKCC2 surface expression in mammalian cells: down-regulation by novel interaction with aldolase B," Journal of Biological Chemistry, vol. 282, no. 46, pp. 33817-33830, 2007.

[24] N. Zaarour, N. Defontaine, S. Demaretz, A. Azroyan, L. Cheval, and K. Laghmani, "Secretory carrier membrane protein 2 regulates exocytic insertion of NKCC2 into the cell membrane," The Journal of Biological Chemistry, vol. 286, no. 11, pp. 94899502, 2011.

[25] N. Zaarour, S. Demaretz, N. Defontaine, D. Mordasini, and K. Laghmani, "A highly conserved motif at the $\mathrm{COOH}$ terminus dictates endoplasmic reticulum exit and cell surface expression of NKCC2," Journal of Biological Chemistry, vol. 284, no. 32, pp. 21752-21764, 2009.

[26] N. Zaarour, S. Demaretz, N. Defontaine, Y. Zhu, and K. Laghmani, "Multiple evolutionarily conserved di-leucine like motifs in the carboxyl terminus control the anterograde trafficking of 
NKCC2," The Journal of Biological Chemistry, vol. 287, no. 51, pp. 42642-42653, 2012.

[27] S. Mao, T. Garzon-Muvdi, M. Di Fulvio et al., "Molecular and functional expression of cation-chloride cotransporters in dorsal root ganglion neurons during postnatal maturation," Journal of Neurophysiology, vol. 108, no. 3, pp. 834-852, 2012.

[28] M. Di Fulvio and J. Gomez-Cambronero, "Phospholipase D (PLD) gene expression in human neutrophils and HL-60 differentiation," Journal of Leukocyte Biology, vol. 77, no. 6, pp. 999-1007, 2005.

[29] M. Flagella, L. L. Clarke, M. L. Miller et al., "Mice lacking the basolateral $\mathrm{Na}-\mathrm{K}-2 \mathrm{Cl}$ cotransporter have impaired epithelial chloride secretion and are profoundly deaf," The Journal of Biological Chemistry, vol. 274, no. 38, pp. 26946-26955, 1999.

[30] G. Elia, "Cell surface protein biotinylation for SDS-PAGE analysis," Methods in Molecular Biology, vol. 869, pp. 361-372, 2012.

[31] P. A. Ortiz, "cAMP increases surface expression of NKCC2 in rat thick ascending limbs: role of VAMP," The American Journal of Physiology-Renal Physiology, vol. 290, no. 3, pp. F608-F616, 2006.

[32] R. Soundararajan, D. Melters, I.-C. Shih, J. Wang, and D. Pearce, "Epithelial sodium channel regulated by differential composition of a signaling complex," Proceedings of the National Academy of Sciences of the United States of America, vol. 106, no. 19, pp. 7804-7809, 2009.

[33] M. Di Fulvio, K. Frondorf, K. M. Henkels, N. Lehman, and J. Gomez-Cambronero, "The Grb2/PLD2 interaction is essential for lipase activity, intracellular localization and signaling in response to EGF," Journal of Molecular Biology, vol. 367, no. 3, pp. 814-824, 2007.

[34] F. J. Alvarez-Leefmans, "Chloride transporters in presynaptic inhibition, pain and neurogenic inflammation," in Physiology and Pathology of Chloride Transporters and Channels in the Nervous System: From Molecules to Diseases, F. J. AlvarezLeefmans and E. Delpire, Eds., pp. 440-470, Academic Press, 1st edition, 2009.

[35] J. A. Payne and B. Forbush III, "Molecular characterization of the epithelial $\mathrm{Na}-\mathrm{K}-\mathrm{Cl}$ cotransporter isoforms," Current Opinion in Cell Biology, vol. 7, no. 4, pp. 493-503, 1995.

[36] J. A. Payne, J.-C. Xu, M. Haas, C. Y. Lytle, D. Ward, and B. Forbush III, "Primary structure, functional expression, and chromosomal localization of the bumetanide-sensitive Na-K$\mathrm{Cl}$ cotransporter in human colon," The Journal of Biological Chemistry, vol. 270, no. 30, pp. 17977-17985, 1995.

[37] F. J. Alvarez-Leefmans, M. León-Olea, J. Mendoza-Sotelo, F. J. Alvarez, B. Antón, and R. Garduo, "Immunolocalization of the $\mathrm{Na}^{+}-\mathrm{K}^{+}-2 \mathrm{Cl}^{-}$cotransporter in peripheral nervous tissue of vertebrates," Neuroscience, vol. 104, no. 2, pp. 569-582, 2001.

[38] S. Marty, R. Wehrlé, F. J. Alvarez-Leefmans, B. Gasnier, and C. Sotelo, "Postnatal maturation of $\mathrm{Na}^{+}, \mathrm{K}^{+}, 2 \mathrm{Cl}^{-}$cotransporter expression and inhibitory synaptogenesis in the rat hippocampus: an immunocytochemical analysis," European Journal of Neuroscience, vol. 15, no. 2, pp. 233-245, 2002.

[39] A. Muñoz, P. Méndez, J. Defelipe, and F. J. Alvarez-Leefmans, "Cation-chloride cotransporters and GABA-ergic innervation in the human epileptic hippocampus," Epilepsia, vol. 48, no. 4, pp. 663-673, 2007.

[40] C. Lytle, J.-C. Xu, D. Biemesderfer, and B. Forbush III, "Distribution and diversity of $\mathrm{Na}-\mathrm{K}-\mathrm{Cl}$ cotransport proteins: a study with monoclonal antibodies," The American Journal of
Physiology-Cell Physiology, vol. 269, no. 6, pp. C1496-C1505, 1995.

[41] B. Kleizen and I. Braakman, "Protein folding and quality control in the endoplasmic reticulum," Current Opinion in Cell Biology, vol. 16, no. 4, pp. 343-349, 2004.

[42] S. Urbé, L. A. Huber, M. Zerial, S. A. Tooze, and R. G. Parton, "Rab11, a small GTPase associated with both constitutive and regulated secretory pathways in PC12 cells," FEBS Letters, vol. 334, no. 2, pp. 175-182, 1993.

[43] M. Ren, G. Xu, J. Zeng, C. De Lemos-Chiarandini, M. Adesnik, and D. D. Sabatini, "Hydrolysis of GTP on rabll is required for the direct delivery of transferrin from the pericentriolar recycling compartment to the cell surface but not from sorting endosomes," Proceedings of the National Academy of Sciences of the United States of America, vol. 95, no. 11, pp. 6187-6192, 1998.

[44] B. Burke, G. Griffiths, H. Reggio, D. Louvard, and G. Warren, "A monoclonal antibody against a 135-K Golgi membrane protein," The EMBO Journal, vol. 1, no. 12, pp. 1621-1628, 1982.

[45] P. Stanley, "Golgi glycosylation," Cold Spring Harbor Perspectives in Biology, vol. 3, no. 4, 2011.

[46] J. Lippincott-Schwartz, L. C. Yuan, J. S. Bonifacino, and R. D. Klausner, "Rapid redistribution of Golgi proteins into the ER in cells treated with brefeldin A: evidence for membrane cycling from Golgi to ER," Cell, vol. 56, no. 5, pp. 801-813, 1989.

[47] J. Lippincott-Schwartz, L. Yuan, C. Tipper, M. Amherdt, L. Orci, and R. D. Klausner, "Brefeldin A's effects on endosomes, lysosomes, and the TGN suggest a general mechanism for regulating organelle structure and membrane traffic," Cell, vol. 67, no. 3, pp. 601-616, 1991.

[48] T. Anelli and R. Sitia, "Protein quality control in the early secretory pathway," The EMBO Journal, vol. 27, no. 2, pp. 315327, 2008.

[49] M. Aebi, "N-linked protein glycosylation in the ER," Biochimica et Biophysica Acta-Molecular Cell Research, vol. 1833, no. 11, pp. 2430-2437, 2013.

[50] J. Breitling and M. Aebi, "N-linked protein glycosylation in the endoplasmic reticulum," Cold Spring Harbor Perspectives in Biology, vol. 5, no. 8, 2013.

[51] A. D. Elbein, "Inhibitors of the biosynthesis and processing of N-linked oligosaccharides," Critical Reviews in Biochemistry, vol. 16, no. 1, pp. 21-49, 1984.

[52] A. D. Elbein, J. E. Tropea, M. Mitchell, and G. P. Kaushal, "Kifunensine, a potent inhibitor of the glycoprotein processing mannosidase I," The Journal of Biological Chemistry, vol. 265, no. 26, pp. 15599-15605, 1990.

[53] F. Wang, W. Song, G. Brancati, and L. Segatori, "Inhibition of endoplasmic reticulum-associated degradation rescues native folding in loss of function protein misfolding diseases," The Journal of Biological Chemistry, vol. 286, no. 50, pp. 4345443464, 2011.

[54] A. D. Elbein, J. K. Kerbacher, C. J. Schwartz, and E. A. Sprague, "Kifunensine inhibits glycoprotein processing and the function of the modified LDL receptor in endothelial cells," Archives of Biochemistry and Biophysics, vol. 288, no. 1, pp. 177-184, 1991.

[55] A. D. Elbein, R. Solf, P. R. Dorling, and K. Vosbeck, "Swainsonine: an inhibitor of glycoprotein processing," Proceedings of the National Academy of Sciences of the United States of America, vol. 78, no. 12, pp. 7393-7397, 1981.

[56] J. M. H. van den Elsen, D. A. Kuntz, and D. R. Rose, "Structure of Golgi alpha-mannosidase II: a target for inhibition of growth and metastasis of cancer cells," The EMBO Journal, vol. 20, no. 12, pp. 3008-3017, 2001. 
[57] J. P. Arroyo, K. T. Kahle, and G. Gamba, "The SLC12 family of electroneutral cation-coupled chloride cotransporters," Molecular Aspects of Medicine, vol. 34, no. 2-3, pp. 288-298, 2013.

[58] A. Hannemann and P. W. Flatman, "Phosphorylation and transport in the Na-K-2Cl cotransporters, NKCC1 and NKCC2A, compared in HEK-293 cells," PLoS ONE, vol. 6, no. 3, Article ID e17992, 2011.

[59] T. Gerelsaikhan, M. N. Parvin, and R. J. Turner, "Biogenesis and topology of the secretory $\mathrm{Na}^{+}-\mathrm{K}^{+}-2 \mathrm{Cl}^{-}$cotransporter (NKCCl) studied in intact mammalian cells," Biochemistry, vol. 45, no. 39, pp. 12060-12067, 2006.

[60] T. Gerelsaikhan and R. J. Turner, "Transmembrane topology of the secretory $\mathrm{Na}^{+}-\mathrm{K}^{+}-2 \mathrm{Cl}^{-}$cotransporter $\mathrm{NKCCl}$ studied by in vitro translation," The Journal of Biological Chemistry, vol. 275, no. 51, pp. 40471-40477, 2000.

[61] T. Gerelsaikhan and R. J. Turner, "Membrane topology and function of the secretory $\mathrm{Na}^{+}-\mathrm{K}^{+}-2 \mathrm{Cl}^{-}$cotransporter (NKCC1)," Journal of Korean Medical Science, vol. 15, supplement 1, pp. S3-S4, 2000.

[62] M. N. Parvin, T. Gerelsaikhan, and R. J. Turner, "Regions in the cytosolic C-terminus of the secretory $\mathrm{Na}^{+}-\mathrm{K}^{+}-2 \mathrm{Cl}^{-}$ cotransporter $\mathrm{NKCCl}$ are required for its homodimerization," Biochemistry, vol. 46, no. 33, pp. 9630-9637, 2007.

[63] M. D. Plotkin, M. R. Kaplan, L. N. Peterson, S. R. Gullans, S. C. Hebert, and E. Delpire, "Expression of the $\mathrm{Na}(+)-\mathrm{K}(+)-$ 2Cl- cotransporter BSC2 in the nervous system," The American Journal of Physiology, vol. 272, no. 1, part 1, pp. C173-C183, 1997.

[64] M. Carmosino, I. Giménez, M. Caplan, and B. Forbush, "Exon loss accounts for differential sorting of $\mathrm{Na}-\mathrm{K}-\mathrm{Cl}$ cotransporters in polarized epithelial cells," Molecular Biology of the Cell, vol. 19, no. 10, pp. 4341-4351, 2008.

[65] X. C. Zhu, R. Sarker, J. R. Horton et al., "Nonsynonymous single nucleotide polymorphisms of NHE3 differentially decrease NHE3 transporter activity," The American Journal of Physiology-Cell Physiology, vol. 308, no. 9, pp. C758-C766, 2015.

[66] J. Li, F. Xia, and R. A. F. Reithmeier, "N-glycosylation and topology of the human SLC26 family of anion transport membrane proteins," The American Journal of Physiology-Cell Physiology, vol. 306, no. 10, pp. C943-C960, 2014.

[67] K. Varga, A. Jurkuvenaite, J. Wakefield et al., "Efficient intracellular processing of the endogenous cystic fibrosis transmembrane conductance regulator in epithelial cell lines," The Journal of Biological Chemistry, vol. 279, no. 21, pp. 22578-22584, 2004.

[68] J. Ding, J. Ponce-Coria, and E. Delpire, "A trafficking-deficient mutant of KCC3 reveals dominant-negative effects on $\mathrm{K}-\mathrm{Cl}$ cotransport function," PLoS ONE, vol. 8, no. 4, Article ID e61112, 2013.

[69] S.-R. Chen, L. Zhu, H. Chen, L. Wen, G. Laumet, and H.-L. Pan, "Increased spinal cord $\mathrm{Na}^{+}-\mathrm{K}^{+}-2 \mathrm{Cl}^{-}$cotransporter-1 (NKCC1) activity contributes to impairment of synaptic inhibition in paclitaxel-induced neuropathic pain," The Journal of Biological Chemistry, vol. 289, no. 45, pp. 31111-31120, 2014.

[70] J. Li, J. Quilty, M. Popov, and R. A. F. Reithmeier, "Processing of $\mathrm{N}$-linked oligosaccharide depends on its location in the anion exchanger, AE1, membrane glycoprotein," Biochemical Journal, vol. 349, part 1, pp. 51-57, 2000.

[71] R. S. Hoover, E. Poch, A. Monroy et al., "N-glycosylation at two sites critically alters thiazide binding and activity of the rat thiazide-sensitive $\mathrm{Na}^{+}: \mathrm{Cl}^{-}$cotransporter," Journal of the American Society of Nephrology, vol. 14, no. 2, pp. 271-282, 2003.
[72] T.-Y. Weng, W.-T. Chiu, H.-S. Liu et al., "Glycosylation regulates the function and membrane localization of KCC4," Biochimica et Biophysica Acta-Molecular Cell Research, vol. 1833, no. 5, pp. 1133-1146, 2013.

[73] E. Moreno, P. S. Cristóbal, M. Rivera, N. Vázquez, N. A. Bobadilla, and G. Gamba, "Affinity-defining domains in the $\mathrm{Na}-\mathrm{Cl}$ cotransporter: a different location for $\mathrm{CI}^{-}$and thiazide binding," The Journal of Biological Chemistry, vol. 281, no. 25, pp. 1726617275, 2006. 

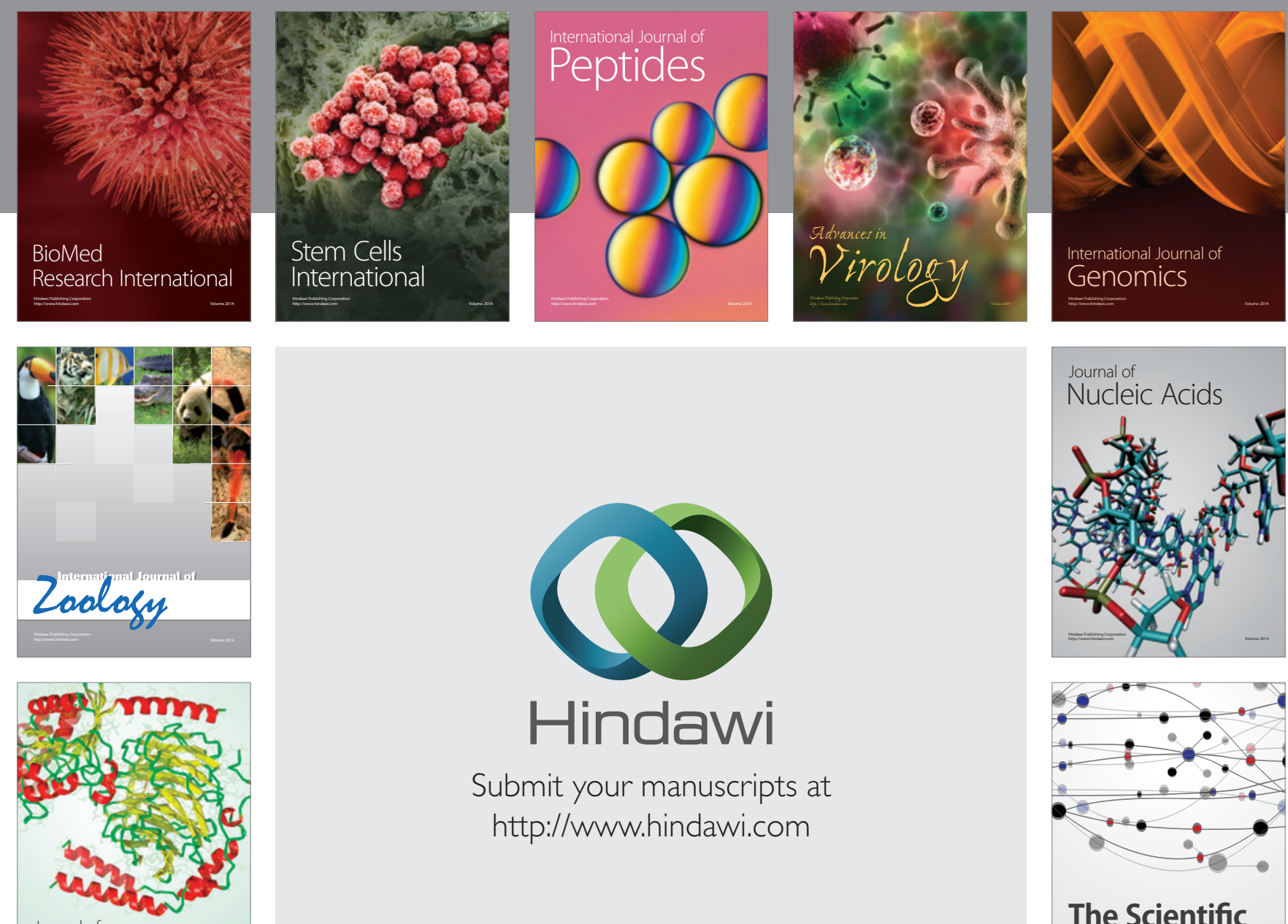

Submit your manuscripts at

http://www.hindawi.com

Journal of
Signal Transduction
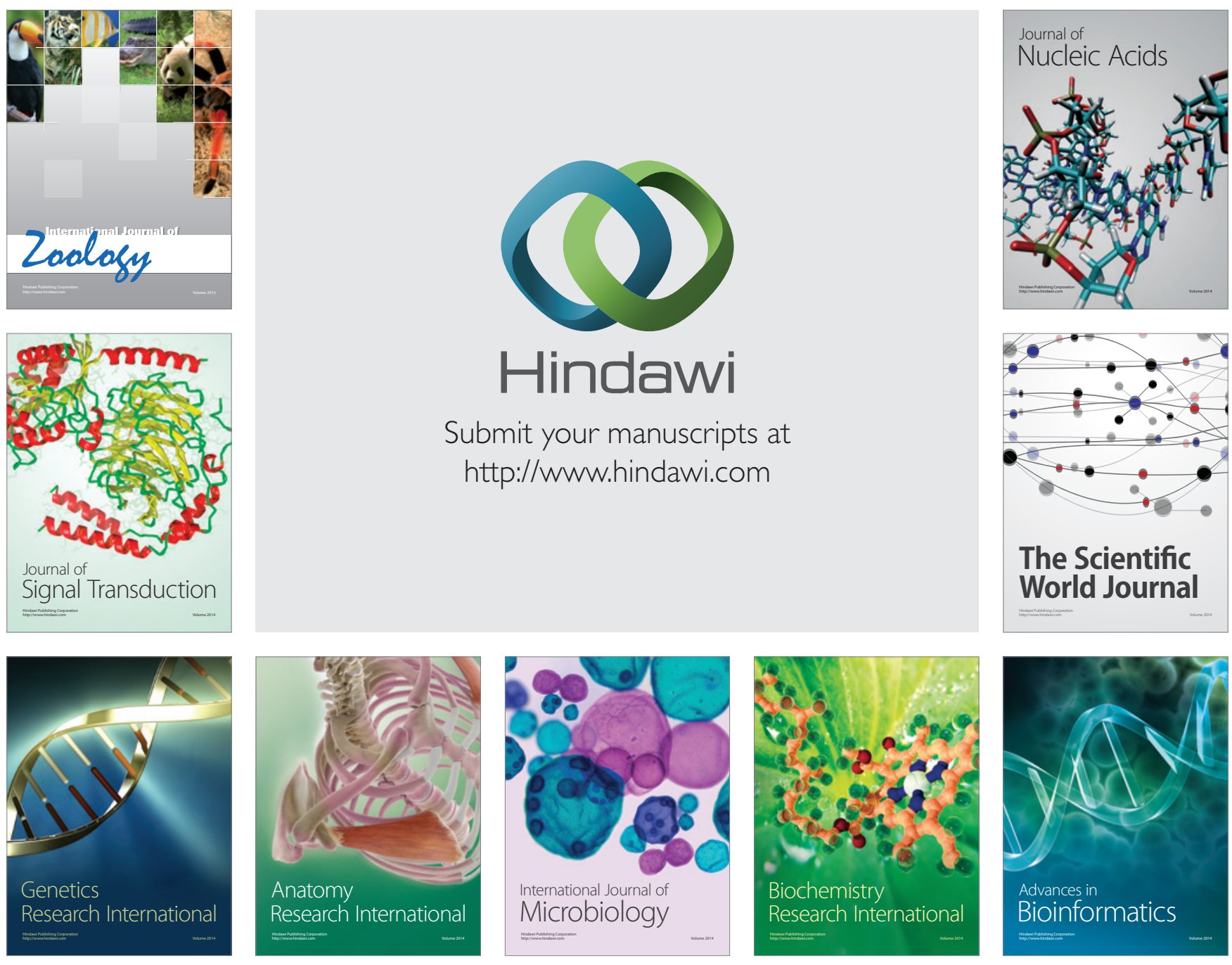

The Scientific World Journal
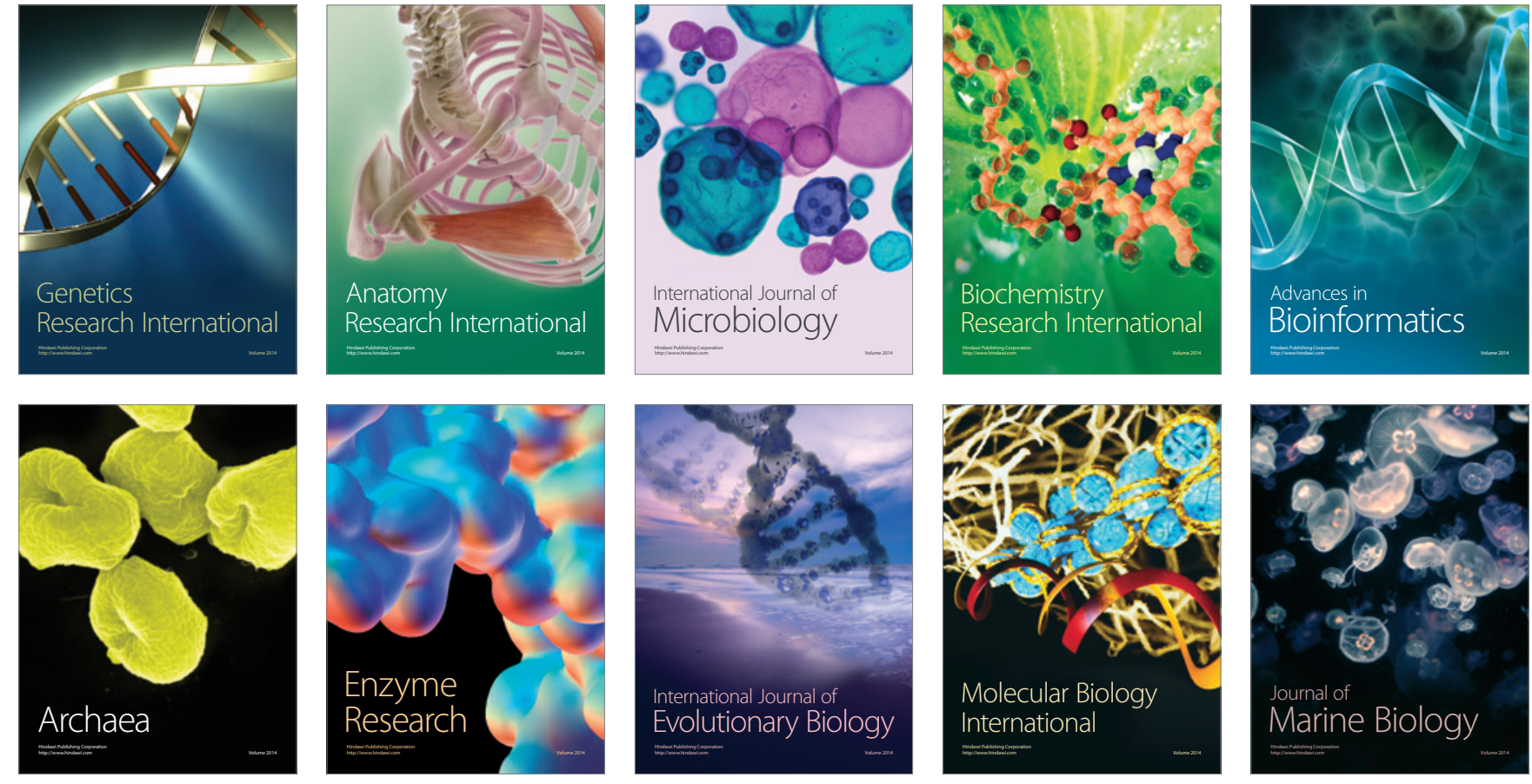